\title{
Immune gene prognostic signature for disease free survival of gastric cancer Translational research of an artificial intelligence survival predictive system
}

\section{zhiqiao zhang ( $\sim$ sdgrxjbk@163.com )}

The Affiliated Chencun Hospital of Shunde Hospital,Southern Medical University https://orcid.org/0000-0003-4631-8818

\section{Tingshan He}

Department of Infectious Diseases, Shunde Hospital, Southern Medical University, Shunde, Guangdong, China

\section{Liwen Huang}

Department of Infectious Diseases, Shunde Hospital, Southern Medical University, Shunde, Guangdong, China

Jing Li

Department of Infectious Diseases, Shunde Hospital, Southern Medical University, Shunde, Guangdong, China

\section{Peng Wang}

Department of Infectious Diseases, Shunde Hospital, Southern Medical University, Shunde, Guangdong, China

\section{Research}

Keywords: Immune gene, transcription factor, gastric cancer, disease free survival, prognostic signature

Posted Date: June 18th, 2020

DOI: https://doi.org/10.21203/rs.3.rs-35150/v1

License: (c) (1) This work is licensed under a Creative Commons Attribution 4.0 International License. Read Full License

Version of Record: A version of this preprint was published at Computational and Structural Biotechnology Journal on January 1st, 2021. See the published version at https://doi.org/10.1016/j.csbj.2021.04.025. 


\section{Abstract \\ Background}

The progress of artificial intelligence algorithms and massive data provide new ideas and choices for individual mortality risk prediction for cancer patients. The current research focused on depict immune gene related regulatory network and develop an artificial intelligence survival predictive system for disease free survival of gastric cancer.

\section{Methods}

Multi-task logistic regression algorithm, Cox survival regression algorithm, and Random survival forest algorithm were used to develop the artificial intelligence survival predictive system.

\section{Results}

Nineteen transcription factors and seventy immune genes were identified to construct a transcription factor regulatory network of immune genes. Multivariate Cox regression identified fourteen immune genes as prognostic markers. These immune genes were used to construct a prognostic signature for gastric cancer. Concordance indexes were $0.800,0.809$, and 0.856 for 1-, 3- and 5 -year survival. An interesting artificial intelligence survival predictive system was developed based on three artificial intelligence algorithms for gastric cancer. Gastric cancer patients with high risk score have poor survival than patients with low risk score.

\section{Conclusions}

The current study constructed a transcription factor regulatory network and developed two artificial intelligence survival prediction tools for disease free survival of gastric cancer patients. These artificial intelligence survival prediction tools are helpful for individualized treatment decision.

\section{Background}

Epidemiological data demonstrated gastric cancer (GC) is one of the leading digestive malignant tumors and ranks second for tumor-related deaths with 782,685 deaths in 2018 [1]. Although advances in early screening, diagnosis, and treatments reduced mortality to some extent [2,3], the prognosis of gastric cancer patients were still unsatisfactory [4]. From a clinical point of view, early identification of high risk GC patients with high mortality and more precise individualized treatments are helpful to improve the prognosis of high risk GC patients. Therefore, reliable and precise individual mortality risk prediction is of great significance for optimizing individual treatment effect. 
Great progress has been made in precision medicine in recent years [5, 6]. Precision medical predictive tools can be used in predicting individual mortality risk in different time-points and the efficacy for different treatments. [7-9]. However, precision medical predictive tools for predicting mortality risk of gastric cancer patients have not been able to meet the needs of individualized treatment.

Bioinformatics advances provided tremendous impetus to precision medical research in tumorigenesis and progression. Bioinformatics is helpful to explore the intrinsic biological regulatory mechanisms and potential pathways for tumorigenesis and progression [10-13]. In recent years, more and more studies have focused on the important role of immune microenvironment in tumorigenesis and progression [14, 15]. Jiang et al. developed a prognostic signature in predicting the prognosis of gastric cancer patients [16]. Yang et al. developed a prognostic signature based on immune genes to predict overall survival of GC patients [17]. However, this prognostic signature did not provide calculation formula and was limited for clinical application. Therefore, it is valuable to develop individualized precision medical predictive tools for early identification of gastric cancer with high mortality risk.

Precision medical predictive tools can provide individualized mortality risk prediction and help clinicians early identify patients with high mortality risk. Recently, our team has successfully developed several precision medical predictive tools based on genetic data for different tumors [18-20]. In recent years, the development of artificial intelligence algorithms provides more choices for the predictive studies of tumor prognosis. Multi-task logistic regression algorithm, Cox survival regression algorithm, and random survival forest algorithm have been used to improve the accuracy of predictive models and prognostic models [21-26]. Therefore the current research was devoted to explore potential immune regulatory mechanism for prognosis of GC and construct artificial intelligence survival prediction tools for predicting individual mortality risk in different time-points.

\section{Methods}

\section{Study Datasets}

Model dataset was downloaded from TCGA database, involving 22,412 mRNAs from 375 GC specimens and 32 normal specimens. Two hundred and sixty five GC patients were included after moving patients without enough follow-up information. Validation dataset (GSE62254) was obtained from GEO database. GSE62254 dataset contained two hundred and seventy nine patients and 19,765 mRNAs (GPL570 platform). Probe IDs were translated to official gene symbols according to Gencode.v29 background file.

\section{Differentially Expressed Analyses}

Differentially expressed analyses (Fig. 1A) identified 6047 differentially expressed mRNAs (3539 upregulated and 2508 down-regulated) out of 22,412 mRNAs. There were 3691 immune genes after interaction between mRNA symbols and immune genes from ImmPort database. Differentially expressed 
analyses (Fig. 1B) identified 2352 differentially expressed immune genes (1235 up-regulated and 1117 down-regulated).

\section{Statistical Analyses And Artificial Intelligence Algorithms}

Statistical analyses were carried out by using SPSS Statistics 19.0 (SPSS Inc.,USA ). Artificial intelligence algorithms were performed by Python language 3.7.2 and R software 3.5.2. Artificial intelligence algorithms were carried out according to the original articles: Multi-task logistic regression [23, 30], Cox survival regression [24], and Random survival forest [21, 22]. $P$ value $<0.05$ was considered statistically significant.

\section{Results}

\section{Study Datasets}

Flow chart in current study was presented in Supplementary Fig.1. Model cohort contained 265 GC patients and validation cohort contained $279 \mathrm{GC}$ patients. The comparisons of clinical parameters between model cohort and validation cohort were presented in Table 1. 
Table 1

The clinical features of patients in model cohort and validation cohort

\begin{tabular}{|c|c|c|c|}
\hline & TCGA cohort & GSE62254 cohort & $P$ value \\
\hline Patient number & 265 & 279 & \\
\hline Death $[n(\%)]$ & $98(37.0)$ & $152(54.5)$ & $<0.001$ \\
\hline Survival time for living patients(mean $\pm S D$, month) & $19.6(12.3,32.2)$ & $60.0(49.0,76.0)$ & $<0.001$ \\
\hline Survival time for dead patients (mean $\pm S D$, month) & $10.6(6.0,15.4)$ & $9.4(3.9,18.1)$ & 0.827 \\
\hline Age (mean $\pm S D$, year) & $64.4 \pm 10.6$ & $61.9 \pm 11.3$ & 0.008 \\
\hline Male $[(n) \%]$ & $175(66.0)$ & 181(94.9) & 0.776 \\
\hline AJCC Stage (IV) & 23 & 75 & $<0.001$ \\
\hline AJCC Stage (III) & 103 & 86 & \\
\hline AJCC Stage (II) & 91 & 89 & \\
\hline AJCC Stage (I) & 41 & 29 & \\
\hline AJCC Stage (NA) & 7 & 0 & \\
\hline AJCC PT (T4) & 66 & 20 & $<0.001$ \\
\hline AJCC PT (T3) & 121 & 84 & \\
\hline AJCC PT (T2) & 62 & 175 & \\
\hline AJCC PT (T1) & 16 & 0 & \\
\hline AJCC PT (NA) & 0 & 0 & \\
\hline AJCC PN (N3) & 53 & 50 & 0.006 \\
\hline AJCC PN (N2) & 55 & 73 & \\
\hline AJCC PN (N1) & 67 & 119 & \\
\hline AJCC PN (N0) & 88 & 37 & \\
\hline AJCC PN (NA) & 2 & 0 & \\
\hline AJCC PM (M1) & 22 & 27 & 0.578 \\
\hline AJCC PM (M0) & 243 & 252 & \\
\hline AJCC PM (NA) & 0 & 0 & \\
\hline Targeted molecular therapy (Yes) & 78 & NA & \\
\hline
\end{tabular}

Note: NA, missing data; SD: standard deviation; AJCC: American Joint Committee on Cancer. 


\begin{tabular}{|llll|}
\hline & TCGA cohort & GSE62254 cohort & $P$ value \\
\hline Targeted molecular therapy (No) & 79 & NA & NA \\
\hline Targeted molecular therapy (NA) & 108 & NA \\
\hline Radiation treatment adjuvant (Yes) & 0 & NA \\
\hline Radiation treatment adjuvant (No) & 155 & NA \\
\hline Radiation treatment adjuvant (NA) & 110 & NA \\
\hline Barretts esophagus (Yes) & 12 & NA \\
\hline Barretts esophagus (No) & 151 & NA \\
\hline Barretts esophagus (NA) & 102 & NA \\
\hline H pylori infection (Yes/No/NA) & 15 & NA \\
\hline H pylori infection (No) & 117 & NA \\
\hline H pylori infection (NA) & 133 & Committee on Cancer. \\
\hline Note: NA, missing data; SD: standard deviation; AJCC: American Joint &
\end{tabular}

\section{Differentially expressed analyses}

Differentially expressed analyses (Fig.1A) identified 6047 differentially expressed mRNAs (3539 upregulated and 2508 down-regulated) out of 22,412 mRNAs. There were 3691 immune genes after interaction between mRNA symbols and immune genes from ImmPort database. Differentially expressed analyses (Fig.1B) identified 2352 differentially expressed immune genes (1235 up-regulated and 1117 down-regulated).

\section{Functional Enrichment Analyses}

Potential biological functions of immune genes were explored through Gene Ontology (GO) functional enrichment analyses. Bar plot (Fig. 1C), bubble plot (Supplementary Fig. 2) and chord plot (Supplementary Fig. 3) indicated potential biological functions of immune genes as following: collagencontaining extracellular matrix, extracellular matrix, endocrine process, extracellular structure organization, regulation of systemic arterial blood pressure by hormone, regulation of systemic arterial blood pressure, positive regulation of response to external stimulus, extracellular matrix organization, regulation of systemic arterial blood pressure mediated by a chemical signal, platelet alpha granule lumen, platelet alpha granule, regulation of inflammatory response, regulation of digestive system process, secretory granule lumen, and cytoplasmic vesicle lumen. 


\section{Prognostic Immune Genes And Regulatory Network}

There were 160 immune genes identified as prognostic markers for GC via univariate Cox regression. Transcription factor is a key link in the molecular regulatory pathway. To better understand the regulatory relationship between transcription factors and immune genes, the current study performed correlation analyses to identify transcription factors closely related to immune genes. According to cut off values of |correlation coefficient $>0.5$ and $P$ value $<0.01,19$ transcription factors and 70 immune genes were identified to construct a transcription factor regulatory network of immune genes (Fig. 2) via Cytoscape v3.6.1 [31].

\section{Construction Of Prognostic Signature}

Out of previous prognostic immune genes, fourteen immune genes were identified as independent risk factors for DFS (Table 2). The risk factor forest chart and survival curve chart of fourteen immune immune genes were presented in Fig. 3 and Fig. 4. The prognostic signature was calculated with the following formula: The risk score $=(0.5307 * \mathrm{CIDEA})+(0.665 * \mathrm{VSIG} 1)+$ 
Table 2

Information of prognostic genes.

Univariate analysis

\begin{tabular}{|c|c|c|c|c|c|c|c|}
\hline Gene & $H R$ & $95 \% \mathrm{Cl}$ & $\begin{array}{l}P \text { - } \\
\text { value }\end{array}$ & coefficient & HR & $95 \% \mathrm{Cl}$ & $\begin{array}{l}P- \\
\text { value }\end{array}$ \\
\hline CIDEA(High/Low) & 1.949 & $\begin{array}{l}1.302- \\
2.916\end{array}$ & 0.001 & 0.531 & 1.700 & $\begin{array}{l}1.104- \\
2.620\end{array}$ & 0.016 \\
\hline VSIG1(High/Low) & 1.813 & $\begin{array}{l}1.204- \\
2.728\end{array}$ & 0.004 & 0.665 & 1.945 & $\begin{array}{l}1.242- \\
3.044\end{array}$ & 0.004 \\
\hline B3GNTL1(High/Low) & 1.683 & $\begin{array}{l}1.125- \\
2.517\end{array}$ & 0.011 & 0.621 & 1.860 & $\begin{array}{l}1.122- \\
3.084\end{array}$ & 0.016 \\
\hline FERMT1(High/Low) & 0.605 & $\begin{array}{l}0.404- \\
0.907\end{array}$ & 0.015 & -0.574 & 0.563 & $\begin{array}{l}0.343- \\
0.925\end{array}$ & 0.023 \\
\hline RETN(High/Low) & 1.798 & $\begin{array}{l}1.202- \\
2.690\end{array}$ & 0.004 & 0.700 & 2.015 & $\begin{array}{l}1.267- \\
3.205\end{array}$ & 0.003 \\
\hline NLRC5(High/Low) & 0.631 & $\begin{array}{l}0.423- \\
0.942\end{array}$ & 0.024 & -0.892 & 0.410 & $\begin{array}{l}0.253- \\
0.664\end{array}$ & 0.000 \\
\hline GJB6(High/Low) & 1.777 & $\begin{array}{l}1.185- \\
2.664\end{array}$ & 0.005 & 0.696 & 2.006 & $\begin{array}{l}1.297- \\
3.102\end{array}$ & 0.002 \\
\hline GPC3(High/Low) & 1.930 & $\begin{array}{l}1.282- \\
2.906\end{array}$ & 0.002 & 0.791 & 2.205 & $\begin{array}{l}1.409- \\
3.450\end{array}$ & 0.001 \\
\hline CMTM1(High/Low) & 1.840 & $\begin{array}{l}1.223- \\
2.769\end{array}$ & 0.003 & 0.996 & 2.707 & $\begin{array}{l}1.537- \\
4.765\end{array}$ & 0.001 \\
\hline IFI44L(High/Low) & 1.508 & $\begin{array}{l}1.009- \\
2.253\end{array}$ & 0.045 & 0.661 & 1.936 & $\begin{array}{l}1.214- \\
3.088\end{array}$ & 0.006 \\
\hline LRP8(High/Low) & 0.629 & $\begin{array}{l}0.421- \\
0.941\end{array}$ & 0.024 & -0.632 & 0.531 & $\begin{array}{l}0.330- \\
0.856\end{array}$ & 0.009 \\
\hline FGB(High/Low) & 1.573 & $\begin{array}{l}1.054- \\
2.348\end{array}$ & 0.027 & 0.753 & 2.122 & $\begin{array}{l}1.340- \\
3.362\end{array}$ & 0.001 \\
\hline NOX1(High/Low) & 0.577 & $\begin{array}{l}0.383- \\
0.870\end{array}$ & 0.009 & -0.587 & 0.556 & $\begin{array}{l}0.348- \\
0.888\end{array}$ & 0.014 \\
\hline CDSN(High/Low) & 1.652 & $\begin{array}{l}1.103- \\
2.473\end{array}$ & 0.015 & 0.566 & 1.761 & $\begin{array}{l}1.108- \\
2.798\end{array}$ & 0.017 \\
\hline
\end{tabular}

Note: $\mathrm{HR}$, hazard ratio; $\mathrm{Cl}$, confidence interval. The medians of gene expression values were used as cut-off values to stratify gene expression values into high expression group (as value 1) and low expression group (as value 0 ).

$(0.6206 *$ B3GNTL1)+(-0.5741*FERMT1)+(0.7004*RETN $)+(-0.8919 * N L R C 5)+(0.6959 * G J B 6)+$ $(0.7907 * \mathrm{GPC} 3)+(0.9957 * \mathrm{CMTM} 1)+(0.6608 * \mathrm{IFI} 44 \mathrm{~L})+(-0.6322 * \mathrm{LRP} 8)+(0.7525 * \mathrm{FGB})+(-0.5867 * \mathrm{NOX} 1)+$ 
$\left(0.5657^{\star} \mathrm{CDSN}\right)$. A prognostic nomogram was presented in Fig. 5.

Survival curve analyses of immune genes (Fig. 3) demonstrated that DFS were significantly different between different immune expression status $(P<0.05)$. The predictive value distribution chart and survival status scatter plot were presented in Supplementary Fig. 4 and Supplementary Fig. 5.

\section{Predictive Performance In Model Cohort}

According to median of prognostic signature score, Fig. $6 \mathrm{~A}$ demonstrated that there was significant difference between two groups. Concordance indexes were $0.800,0.809$, and 0.856 for 1 -year, 3-year, and 5-year DFS (Fig. 6B). Calibration curves were showed in Supplementary Fig. 6.

\section{Predictive Performance In Validation Cohort}

Survival curves (Fig. 7A) demonstrated that DFS in high risk group was significantly poor than that in low risk group. Concordance indexes were $0.911,0.815$, and 0.815 for 1-year, 3-year, and 5-year DFS (Fig. 7B). Calibration curves were showed in Supplementary Fig. 7. Decision curve charts were presented in Supplementary Fig. 8.

\section{Artificial Intelligence Survival Predictive System}

An artificial intelligence survival predictive system was developed to provide on-line prediction for DFS (Fig. 8). This artificial intelligence survival predictive system was provided at: https://zhangzhiqiao7.shinyapps.io/Smart_Cancer_Survival_Predictive_System_15_GC_D1006/. Three individual mortality risk predictive curves predicted by, Multi-task logistic regression (MTLR) algorithm (Fig. 8A), Random survival forest (RFS) algorithm (Fig. 8B), and Cox survival regression algorithm (Fig. 8C). This artificial intelligence survival predictive system could provide $95 \%$ confidence interval of predicted mortality and median survival time for an individual patient.

\section{Gene Survival Analysis Screen System}

A precision medical predictive tool named Gene Survival Analysis Screen System was developed to explore the prognostic influence of immune genes in different subgroups (Fig. 9). Gene Survival Analysis Screen System was provided at: https://zhangzhiqiao7.shinyapps.io/Gene_Survival_Subgroup_Analysis_15_GC_D1006/.

\section{Independence Assessment}


In model cohort, this prognostic signature was an independent risk factor for DFS (Table 3). In validation cohort, prognostic signature, American Joint Committee on Cancer PM, and gender were independent risk factors for DFS. 
Table 3

Results of Cox regression analyses

Univariate analysis

$\mathrm{HR} \quad 95 \% \mathrm{Cl}$

\section{Multivariate analysis}

\begin{tabular}{|c|c|c|c|c|c|c|c|}
\hline & $\mathrm{HR}$ & $95 \% \mathrm{Cl}$ & $\begin{array}{l}P- \\
\text { value }\end{array}$ & Coefficient & $\mathrm{HR}$ & $95 \% \mathrm{Cl}$ & $\begin{array}{l}P \text { - } \\
\text { value }\end{array}$ \\
\hline \multicolumn{8}{|l|}{ TCGA cohort $(n=265)$} \\
\hline Age(High/Low) & 0.858 & $\begin{array}{l}0.577- \\
1.274\end{array}$ & 0.447 & 0.265 & 1.303 & $\begin{array}{l}0.854- \\
1.988\end{array}$ & 0.220 \\
\hline Gender (Male/Female) & 1.607 & $\begin{array}{l}1.072- \\
2.409\end{array}$ & 0.022 & 0.114 & 1.120 & $\begin{array}{l}0.610- \\
2.058\end{array}$ & 0.714 \\
\hline AJCC PT (T3-4/T1-2) & 1.385 & $\begin{array}{l}0.876- \\
2.191\end{array}$ & 0.164 & 0.424 & 1.527 & $\begin{array}{l}0.885- \\
2.635\end{array}$ & 0.128 \\
\hline AJCC PN (N2-3/N0-1) & 1.626 & $\begin{array}{l}1.094- \\
2.417\end{array}$ & 0.016 & 0.260 & 1.296 & $\begin{array}{l}0.753- \\
2.233\end{array}$ & 0.349 \\
\hline AJCC PM (M1/M0) & 1.056 & $\begin{array}{l}0.512- \\
2.178\end{array}$ & 0.883 & -0.098 & 0.907 & $\begin{array}{l}0.435- \\
1.891\end{array}$ & 0.794 \\
\hline AJCC stage $(\mathrm{IV}, \mathrm{III} / \mathrm{II}, \mathrm{I})$ & 1.872 & $\begin{array}{l}1.173- \\
2.988\end{array}$ & 0.009 & 0.409 & 1.505 & $\begin{array}{l}0.936- \\
2.421\end{array}$ & 0.092 \\
\hline $\begin{array}{l}\text { Prognostic model } \\
\text { (High/Low) }\end{array}$ & 6.011 & $\begin{array}{l}3.685- \\
9.807\end{array}$ & $<0.001$ & 1.809 & 6.103 & $\begin{array}{l}3.693- \\
10.080\end{array}$ & $<$ \\
\hline \multicolumn{8}{|l|}{$\begin{array}{l}\text { GSE62254 cohort }(n= \\
279)\end{array}$} \\
\hline Age(High/Low) & 1.347 & $\begin{array}{l}0.979- \\
1.853\end{array}$ & 0.068 & 0.257 & 1.292 & $\begin{array}{l}0.935- \\
1.786\end{array}$ & 0.120 \\
\hline Gender (Male/Female) & 3.546 & $\begin{array}{l}2.425- \\
5.183\end{array}$ & $\dot{0} 001$ & 0.865 & 2.376 & $\begin{array}{l}1.268- \\
4.453\end{array}$ & 0.007 \\
\hline AJCC PT (T3-4/T1-2) & 2.270 & $\begin{array}{l}1.649- \\
3.125\end{array}$ & $<0.001$ & 0.188 & 1.207 & $\begin{array}{l}0.809- \\
1.801\end{array}$ & 0.356 \\
\hline AJCC PN (N2-3/N0-1) & 2.848 & $\begin{array}{l}2.051- \\
3.956\end{array}$ & $<.001$ & 0.074 & 1.077 & $\begin{array}{l}0.668- \\
1.735\end{array}$ & 0.762 \\
\hline AJCC PM (M1/M0) & 3.501 & $\begin{array}{l}2.265- \\
5.413\end{array}$ & $<001$ & 0.847 & 2.332 & $\begin{array}{l}1.471- \\
3.696\end{array}$ & $\begin{array}{l}< \\
0.001\end{array}$ \\
\hline AJCC stage $(I \mathrm{I}, \mathrm{III} / \mathrm{II}, \mathrm{I})$ & 1.033 & $\begin{array}{l}0.739- \\
1.445\end{array}$ & 0.848 & 0.242 & 1.273 & $\begin{array}{l}0.902- \\
1.798\end{array}$ & 0.170 \\
\hline $\begin{array}{l}\text { Prognostic model } \\
\text { (High/Low) }\end{array}$ & 4.294 & $\begin{array}{l}3.050- \\
6.044\end{array}$ & $<.001$ & 1.293 & 3.645 & $\begin{array}{l}2.542- \\
5.228\end{array}$ & $<.001$ \\
\hline
\end{tabular}




\section{Subgroup Analyses}

Subgroup analyses demonstrated that DFS in high risk group was significantly poor than that in low risk group for different stage groups in both model cohort and validation cohort (Fig. 10).

\section{Clinical Correlation Analyses}

Clinical correlation analyses displayed the correlation coefficient between clinical parameters and immune genes (Fig. 11). Supplementary Fig. 9 depicted correlation significance between clinical parameters and immune genes.

\section{Tumor Infiltrating Immune Cell Correlation Analyses}

Figure 12 showed the correlation coefficient between tumor infiltrating immune cells and immune genes. Supplementary Fig. 10 depicted correlation significance between tumor infiltrating immune cells and immune genes.

\section{Tumor Infiltrating Immune Cells}

Expression of tumor infiltrating immune cells in patients with high risk score and low risk score was presented in Fig. 13. Scatter plots between tumor infiltrating immune cells and immune genes were shown in Fig. 14. Correlation analyses between tumor infiltrating immune cells and prognostic score were shown in Fig. 15.

\section{Discussion}

The current study identified 14 immune genes closely related to the prognosis of gastric cancer. These immune genes may become valuable prognostic biomarkers and potential targets for tumor immunotherapy. The current study constructed a transcription factor regulatory network of immune genes, which may be helpful to understand the potential molecular regulatory mechanisms of tumorigenesis and progression. The current study developed and validated a prognostic signature for DFS of GC patients. In addition, we developed two novel artificial intelligence survival predictive tools to predict individual mortality risk. Additionally, the artificial intelligence survival predictive system could provide $95 \%$ confidence interval of predicted mortality and median survival time. These two artificial intelligence survival predictive tools were convenient in providing individualized mortality risk prediction with advantages of simple operation and intuitive results.

Previous studies have reported several prognostic models for predicting the prognosis of gastric cancer patients $[16,17]$. However, these prognostic models can't predict the mortality risk for an individual patient. In recent years, artificial intelligence algorithms, including Multi-task logistic regression algorithm, 
Cox survival regression algorithm, and random survival forest algorithm, have made great progress in survival prediction [21-26]. With the supports of these advanced artificial intelligence algorithms, we have successfully established artificial intelligence survival predictive system to predict the mortality risk curve for an individual patient. Meanwhile, the current artificial intelligence survival predictive system could provide $95 \%$ confidence interval of predicted mortality and median survival time. Individual level survival prediction and median survival time prediction are the unique prediction ability of our artificial intelligence survival predictive system. In the current study, we creatively applied three artificial intelligence algorithms for predicting the individual mortality risk of cancer patients, providing a feasible idea and valuable reference for the future survival prediction studies.

The current research searched TISIDB databases to explore the biological process of these immune genes (http://cis.hku.hk/TISIDB/index.php). The major biological process of DFFA Like Effector A (CIDEA) is DNA catabolic process, endonucleolytic, temperature homeostasis, and negative regulation of cytokine production. The major biological process of V-set and immunoglobulin domain containing 1 (VSIG1) is tissue homeostasis,epithelial cell development, and epithelial cell morphogenesis. The major biological process of fermitin family member 1 (FERMT1) is ameboidal-type cell migration, establishment or maintenance of cell polarity, and epithelial cell migration. The major biological process of resistin (RETN) is positive regulation of collagen metabolic process, aging and regulation of collagen metabolic process. The major biological process of NLR family, CARD domain containing 5 (NLRC5) is negative regulation of immune system process, response to virus, and positive regulation of cytokine-mediated signaling pathway. The major biological process of gap junction protein, beta $6,30 \mathrm{kDa}$ (GJB6) is cellular glucose homeostasis, response to molecule of bacterial origin, and aging. The major biological process of glypican 3 (GPC3) is retinoid metabolic process, morphogenesis of a polarized epithelium, and ossification. The major biological process of interferon-induced protein 44-like (IFI44L) is response to virus, defense response to virus, and defense response to other organism. The major biological process of low density lipoprotein receptor-related protein 8 (LRP8) is regulation of cell morphogenesis involved in differentiation, retinoid metabolic process, and isoprenoid metabolic process. The major biological process of fibrinogen beta chain (FGB) is extrinsic apoptotic signaling pathway via death domain receptors, vascular process in circulatory system, and adaptive immune response. The major biological process of NADPH oxidase 1 (NOX1) is oxidoreduction coenzyme metabolic process, angiogenesis, and response to oxidative stress. The major biological process of corneodesmosin (CDSN) is keratinocyte differentiation, epidermis development, and epidermal cell differentiation.

The current study identified several valuable prognosis-related biomarkers, which might be potential candidates in targeted treatment. Huang $Y$ et al. reported that methylation level of Cell Death Inducing CIDEA was related with tumor microsatellite instability [32]. Cell proliferation was mediated by NADPH Oxidase 1 (Nox1) expression in colon carcinoma cell lines [33]. High expression of Nox1 in colon cancer accelerated the tumor growth and inhibition of Nox1 might become a new therapeutic strategy for colorectal cancer treatment [34]. Low expression of Interferon Induced Protein 44 Like (IFI44L) impaired antiviral state induced by IFN and might be potential candidate for reduction of virus replication [35]. Glypican 3 (GPC3) was potential immune target for hepatocellular carcinoma through fusing to alpha 
epitope of HBsAg [36]. GPC3-S-Fab could kill GPC3 positive hepatocellular carcinoma cells through natural killer cells [37]. NLR Family CARD Domain Containing 5 (NLRC5) had a weak moderate effect for modulating CD8 + T-cell responses in mice small intestine with rotavirus infection [38]. NLRC5 could mediate proliferation, migration and invasion of renal cell carcinoma through wnt/beta-catenin signaling pathway [39]. Previous studies indicated potential effects of immune genes in molecular biological regulatory mechanisms and pathways of tumorigenesis and progression. The current study constructed a transcription factor regulatory network of immune genes. This regulatory network was helpful to reveal the potential role of immune genes in tumorigenesis and progression.

Tumor infiltrating macrophages could express interleukin 25, which was significantly related to the prognosis of gastric cancer after radical resection [40]. Macrophages could enhance the invasiveness of gastric cancer cells by enhancing the transforming growth factor beta / bone morphogenetic protein pathway [41]. High expression of CD8 + T cells was associated with prognosis and lymph node metastasis of gastric cancer [42]. High regulatory $T$ cells to $C D 8+T$ cells ratio was significantly correlated with poor prognosis of gastric cancer [43]. High infiltration of CD8 $+\mathrm{T}$ cell increased programmed death ligand 1 and decreased survival rate [44]. Tumor antigen could stimulate CD $8+T$ cells $[45,46]$. Neutrophils could inhibit the anti-tumor ability of dendritic cells [47]. Pro-tumoral neutrophils could upregulate immunosuppressive dendritic cells [48]. Dendritic cell infiltration plays an important role in the initiation of primary anti-tumor immune response [49]. Neutrophils could inhibit immune response and accelerate the progress of gastric tumors via GM-CSF-PD-L1 pathway [50].

Advantages of current study: The current research developed artificial intelligence predictive tools for GC patients based on three artificial intelligence algorithms. Artificial intelligence survival predictive system was convenient to predict individualized mortality risk with visual illustration and numerical presentation. The artificial intelligence predictive tools can provide more accurate individual prognostic information and are more suitable to meet the needs of individualized treatment and precision medicine. In order to provide more reliable prognostic information for individual patient, three individual mortality risk predictive curves were presented based on different artificial intelligence algorithms. The current artificial intelligence survival predictive system could provide $95 \%$ confidence interval of predicted mortality and median survival time.

Shortcomings of current study: First, the current research explored clinical significance of immune genes in tumorigenesis and progression based on datasets from public databases. However the conclusions have not yet been verified by researchers' own research data. Second, sample size of the current research is relatively small, weakening the credibility of research conclusions to a certain extent. Prospective basic researches are helpful to further explore the potential role of immune genes in molecular biological regulatory mechanism of tumorigenesis and progression. Third, due to the complexity of artificial intelligence algorithms, the calculation process could not be displayed by simple formula, blocking the application of artificial intelligence algorithms in the field of tumor prognosis to a certain extent.

\section{Conclusion}


The current study constructed a transcription factor regulatory network and developed two artificial intelligence survival prediction tools

(https://zhangzhiqiao7.shinyapps.io/Smart_Cancer_Survival_Predictive_System_15_GC_D1006/ and https://zhangzhiqiao7.shinyapps.io/Gene_Survival_Subgroup_Analysis_15_GC_D1006/) for disease free survival of gastric cancer patients. These artificial intelligence survival prediction tools are helpful to predict individual mortality risk and provide valuable prognostic information for individualized treatment decision.

\section{Abbreviations}

GC: gastric cancer; TCGA: The Cancer Genome Atlas; GEO: the Gene Expression Omnibus; ROC: receiver operating characteristic; DFS: disease free survival; HR: hazard ratio; Cl: confidence interval; AJCC: the American Joint Committee on Cancer; SD: standard deviation; DCA: decision curve analysis.

\section{Declarations}

\section{Ethics approval and consent to participate:}

The studies in TCGA database and GEO database have received ethical approval from ethics committees of their respective research institutes. These studies obtained informed consent from patients before admission. The current study is a second study based on public datasets from TCGA database and GEO database. Details of all patients in public datasets have been anonymously processed and therefore the current research does not involve patients' privacy information. The current study was performed according to public database policy and declaration of Helsinki. TCGA database and GEO database allows researchers to use public datasets for scientific purposes. Ethical approval of this study was waived in accordance with the recommendations of Management Measures for Ethical Review of Clinical Research, Ethics Committees of Shunde Hospital, Southern Medical University because the current study was a retrospective study based on public datasets. Therefore ethical approval and informed consent were not required for the current study.

\section{Consent for publication:}

All authors approved the publication.

\section{Availability of data and materials:}

The study data is available at:

https://zhangzhiqiao7.shinyapps.io/Gene_Survival_Subgroup_Analysis_15_GC_D1006/.

\section{Competing interests:}




\section{Funding:}

The current research was funded by Medical Science and Technology Foundation of Guangdong Province (A2016450 and B2018237).

\section{Authors' contributions:}

Conceptualization, methodology and resources: ZZ, PW, LJ, LH, and TH; Investigation, data curation, formal analysis, validation, software, project administration, and supervision: ZZ, PW, LJ, HL, and TH; Writing and visualization: ZZ and PW; Funding acquisition: ZZ.

\section{Acknowledgements:}

We would like to thank Dr. Gary S Collins (University of Oxford), Dr Manali Rupji (Emory University), Mrs Qingmei Liu for help and support on development of precision medical tools.

Authors' information: Department of Infectious Diseases, Shunde Hospital, Southern Medical University, Shunde, Guangdong, China

\section{References}

1. Bray F, Ferlay J, Soerjomataram I, Siegel RL, Torre LA, Jemal A. Global cancer statistics 2018 : GLOBOCAN estimates of incidence and mortality worldwide for 36 cancers in 185 countries. CA Cancer J Clin. 2018;68:394-424.

2. Wilke H, Muro K, Van Cutsem E, Oh SC, Bodoky G, Shimada Y, Hironaka S, Sugimoto N, Lipatov O, Kim TY, et al. Ramucirumab plus paclitaxel versus placebo plus paclitaxel in patients with previously treated advanc ed gastric or gastro-oesophageal junction adenocarcinoma (RAINBOW): a doubleblind, randomised phase 3 trial. Lancet Oncol. 2014;15:1224-35.

3. Songun I, Putter H, Kranenbarg EM, Sasako M, van de Velde CJ. Surgical treatment of gastric cancer: 15-year follow-up results of the randomised nationwide Dutch D1 D2 trial. Lancet Oncol. 2010;11:439-49.

4. Ajani JA, D'Amico TA, Almhanna K, Bentrem DJ, Chao J, Das P, Denlinger CS, Fanta P, Farjah F, Fuchs CS, et al. Gastric Cancer, Version 3.2016, NCCN Clinical Practice Guidelines in Oncology. J Natl Compr Canc Netw. 2016;14:1286-312.

5. Kim D, Kim DH. Epigenome-Based Precision Medicine in Lung Cancer. Methods Mol Biol. 2018;1856:57-85.

6. Considine B, Petrylak DP. Integrating Novel Targets and Precision Medicine Into Prostate Cancer CarePart 1: The Non-Androgen-T argetable Pathways in Castration-Resistant Prostate Cancer. Oncology (Williston Park). 2019;33:113-8. 
7. Kaidar-Person O, Gil Z, Billan S. Precision medicine in head and neck cancer. Drug Resist Updat. 2018;40:13-6.

8. Mitamura T, Dong P, Ihira K, Kudo M, Watari H. Molecular-targeted therapies and precision medicine for endometrial cancer. Jpn J Clin Oncol. 2019;49:108-20.

9. Nasrazadani A, Thomas RA, Oesterreich S, Lee AV. Precision Medicine in Hormone Receptor-Positive Breast Cancer. Front Oncol. 2018;8:144.

10. Zeng J, Cai X, Hao X, Huang F, He Z, Sun H, Lu Y, Lei J, Zeng W, Liu Y, Luo R. LncRNA FUNDC2P4 down-regulation promotes epithelial-mesenchymal transition by reducing E-cadherin exp ression in residual hepatocellular carcinoma after insufficient radiofrequency ablation. Int J Hyperthermia. 2018;34:802-11.

11. Zhong X, Long Z, Wu S, Xiao M, Hu W. LncRNA-SNHG7 regulates proliferation, apoptosis and invasion of bladder cancer cells assurance guidel ines. J buon. 2018;23:776-81.

12. Shi X, Zhao Y, He R, Zhou M, Pan S, Yu S, Xie Y, Li X, Wang M, Guo X, Qin R. Three-IncRNA signature is a potential prognostic biomarker for pancreatic adenocarcinoma. Oncotarget. 2018;9:24248-59.

13. Huang $Y$, Xiang $B$, Liu $Y$, Wang $Y$, Kan $\mathrm{H}$. LncRNA CDKN2B-AS1 promotes tumor growth and metastasis of human hepatocellular carcinoma by targeting let-7c-5p/NAP1L1 axis. Cancer Lett. 2018;437:56-66.

14. Yu C, Hao X, Zhang S, Hu W, Li J, Sun J, Zheng M. Characterization of the prognostic values of the NDRG family in gastric cancer. Therap Adv Gastroenterol. 2019;12:1756284819858507.

15. Yu C, Zhang Y. Characterization of the prognostic values of CXCR family in gastric cancer. Cytokine. 2019;123:154785.

16. Jiang B, Sun Q, Tong Y, Wang Y, Ma H, Xia X, Zhou Y, Zhang X, Gao F, Shu P. An immune-related gene signature predicts prognosis of gastric cancer. Medicine. 2019;98:e16273.

17. Yang W, Lai Z, Li Y, Mu J, Yang M, Xie J, Xu J. Immune signature profiling identified prognostic factors for gastric cancer. Chin J Cancer Res. 2019;31:463-70.

18. Cheng C, Wang Q, Zhu M, Liu K, Zhang Z. Integrated analysis reveals potential long non-coding RNA biomarkers and their potential biological $f$ unctions for disease free survival in gastric cancer patients. Cancer Cell Int. 2019;19:123.

19. Zhang Z, Ouyang Y, Huang Y, Wang P, Li J, He T, Liu Q. Comprehensive bioinformatics analysis reveals potential IncRNA biomarkers for overall survival in pat ients with hepatocellular carcinoma: an on-line individual risk calculator based on TCGA cohort. Cancer Cell Int. 2019;19:174.

20. Zhang L, Chen S, Wang B, Su Y, Li S, Liu G, Zhang X. An eight-long noncoding RNA expression signature for colorectal cancer patients' prognosis. J Cell Biochem. 2019;120:5636-43.

21. Xu H, Gu X, Tadesse MG, Balasubramanian R. A Modified Random Survival Forests Algorithm for High Dimensional Predictors and Self-Reported Outcomes. J Comput Graph Stat. 2018;27:763-72.

22. Nasejje JB, Mwambi H. Application of random survival forests in understanding the determinants of under-five child mortality in Uganda in the presence of covariates that satisfy the proportional and 
non-proportional hazards assumption. BMC Res Notes. 2017;10:459.

23. Bisaso KR, Karungi SA, Kiragga A, Mukonzo JK, Castelnuovo B. A comparative study of logistic regression based machine learning techniques for prediction of early virological suppression in antiretroviral initiating HIV patients. BMC Med Inform Decis Mak. 2018;18:77.

24. LD F, DY L. Time-dependent covariates in the Cox proportional-hazards regression model. Annu Rev Public Health. 1999;20:145-57.

25. Ruyssinck J, van der Herten J, Houthooft R, Ongenae F, Couckuyt I, Gadeyne B, Colpaert K, Decruyenaere J, De Turck F, Dhaene T. Random Survival Forests for Predicting the Bed Occupancy in the Intensive Care Unit. Comput Math Methods Med. 2016;2016:7087053.

26. Halme HL, Parkkonen L. Across-subject offline decoding of motor imagery from MEG and EEG. Sci Rep. 2018;8:10087.

27. Robinson MD, McCarthy DJ, Smyth GK. edgeR: a Bioconductor package for differential expression analysis of digital gene expression data. Bioinformatics. 2010;26:139-40.

28. Bhattacharya S, Andorf S, Gomes L, Dunn P, Schaefer H, Pontius J, Berger P, Desborough V, Smith T, Campbell J, et al. ImmPort: disseminating data to the public for the future of immunology. Immunol Res. 2014;58:234-9.

29. Mei S, Meyer CA, Zheng R, Qin Q, Wu Q, Jiang P, Li B, Shi X, Wang B, Fan J, et al. Cistrome Cancer: A Web Resource for Integrative Gene Regulation Modeling in Cancer. Cancer Res. 2017;77:e19-22.

30. Alaeddini A, Hong SH. A Multi-way Multi-task Learning Approach for Multinomial Logistic Regression*. An Application in Joint Prediction of Appointment Miss-opportunities across Multiple Clinics. Methods Inf Med. 2017;56:294-307.

31. Shannon P, Markiel A, Ozier O, Baliga NS, Wang JT, Ramage D, Amin N, Schwikowski B, Ideker T. Cytoscape: a software environment for integrated models of biomolecular interaction networks. Genome Res. 2003;13:2498-504.

32. Huang YW, Luo J, Weng YI, Mutch DG, Goodfellow PJ, Miller DS, Huang TH. Promoter hypermethylation of CIDEA, HAAO and RXFP3 associated with microsatellite instability in endo metrial carcinomas. Gynecol Oncol. 2010;117:239-47.

33. de Carvalho DD, Sadok A, Bourgarel-Rey V, Gattacceca F, Penel C, Lehmann M, Kovacic H. Nox1 downstream of 12-lipoxygenase controls cell proliferation but not cell spreading of colon cancer cells. Int J Cancer. 2008;122:1757-64.

34. Stalin J, Garrido-Urbani S, Heitz F, Szyndralewiez C, Jemelin S, Coquoz O, Ruegg C, Imhof BA: Inhibition of host NOX1 blocks tumor growth and enhances checkpoint inhibitor-based immunotherapy. 2019, 2.

35. DeDiego ML, Martinez-Sobrido L, Topham DJ. NOVEL FUNCTIONS OF THE INTERFERON-INDUCED PROTEIN 44-LIKE (IFI44L) AS A FEEDBACK REGULATOR OF HOST AN TIVIRAL RESPONSES. J Virol 2019.

36. Yang JW, Yang DY, Lu FG, Li CH, Chen H, Xie N, Zhao X. GPC3 fused to an alpha epitope of HBsAg acts as an immune target against hepatocellular carcinoma ass ociated with hepatitis $B$ virus. 
Hepatobiliary Pancreat Dis Int. 2011;10:164-70.

37. Wang Y, Liu J, Pan H, Xing J, Wu X, Li Q, Wang Z. A GPC3-targeting Bispecific Antibody, GPC3-S-Fab, with Potent Cytotoxicity. J Vis Exp 2018.

38. Sun T, Ferrero RL, Girardin SE, Gommerman JL, Philpott DJ. NLRC5 deficiency has a moderate impact on immunodominant CD8 + T-cell responses during rotavirus infec tion of adult mice. Immunol Cell Biol. 2019;97:552-62.

39. Wang Q, Ding H, He Y, Li X, Cheng Y, Xu Q, Yang Y, Liao G, Meng X, Huang C, Li J. NLRC5 mediates cell proliferation, migration, and invasion by regulating the $\mathrm{Wnt} / \mid \hat{\mathrm{A}}$-catenin signalling pathway in clear cell renal cell carcinoma. Cancer Lett. 2019;444:9-19.

40. Li J, Liao Y, Ding T, Wang B, Yu X, Chu Y, Xu J, Zheng L. Tumor-infiltrating macrophages express interleukin-25 and predict a favorable prognosis in patients $\mathrm{w}$ ith gastric cancer after radical resection. Oncotarget. 2016;7:11083-93.

41. Shen Z, Kauttu T, Cao J, Sepp?nen H, Vainionp S, Ye Y, Wang S, Mustonen H, Puolakkainen P. Macrophage coculture enhanced invasion of gastric cancer cells via TGF-îA and BMP pathways. Scand J Gastroenterol. 2013;48:466-72.

42. Lee HE, Chae SW, Lee YJ, Kim MA, Lee HS, Lee BL, Kim WH. Prognostic implications of type and density of tumour-infiltrating lymphocytes in gastric cancer. Br J Cancer. 2008;99:1704-11.

43. Ichihara F, Kono K, Takahashi A, Kawaida H, Sugai H, Fujii H. Increased populations of regulatory $T$ cells in peripheral blood and tumor-infiltrating lymphocytes in patients with gastric and esophageal cancers. Clin Cancer Res. 2003;9:4404-8.

44. Thompson ED, Zahurak M, Murphy A, Cornish T, Cuka N, Abdelfatah E, Yang S, Duncan M, Ahuja N, Taube JM, et al. Patterns of PD-L1 expression and CD8 T cell infiltration in gastric adenocarcinomas and associated im mune stroma. Gut. 2017;66:794-801.

45. Carlson LM, De Geer A, Sveinbj?rnsson B, Orrego A, Martinsson T, Kogner P, Levitskaya J. The microenvironment of human neuroblastoma supports the activation of tumor-associated $T$ lymphocytes. Oncoimmunology. 2013;2:e23618.

46. Purwar R, Schlapbach C, Xiao S, Kang HS, Elyaman W, Jiang X, Jetten AM, Khoury SJ, Fuhlbrigge RC, Kuchroo VK, et al. Robust tumor immunity to melanoma mediated by interleukin-9-producing $T$ cells. Nat Med. 2012;18:1248-53.

47. Schuster S, Hurrell B, Tacchini-Cottier F. Crosstalk between neutrophils and dendritic cells: a contextdependent process. J Leukoc Biol. 2013;94:671-5.

48. Okita Y, Ohira M, Tanaka H, Tokumoto M, Go Y, Sakurai K, Toyokawa T, Kubo N, Muguruma K, Sawada T, et al. Alteration of CD4 T cell subsets in metastatic lymph nodes of human gastric cancer. Oncol Rep. 2015;34:639-47.

49. Ananiev J, Gulubova MV, Manolova IM. Prognostic significance of CD83 positive tumor-infiltrating dendritic cells and expression of TGF-bet a 1 in human gastric cancer. Hepatogastroenterology. 2011;58:1834-40. 
50. Wang TT, Zhao YL, Peng LS, Chen N, Chen W, Lv YP, Mao FY, Zhang JY, Cheng P, Teng YS, et al. Tumour-activated neutrophils in gastric cancer foster immune suppression and disease progression thro ugh GM-CSF-PD-L1 pathway. Gut. 2017;66:1900-11.

\section{Figures}
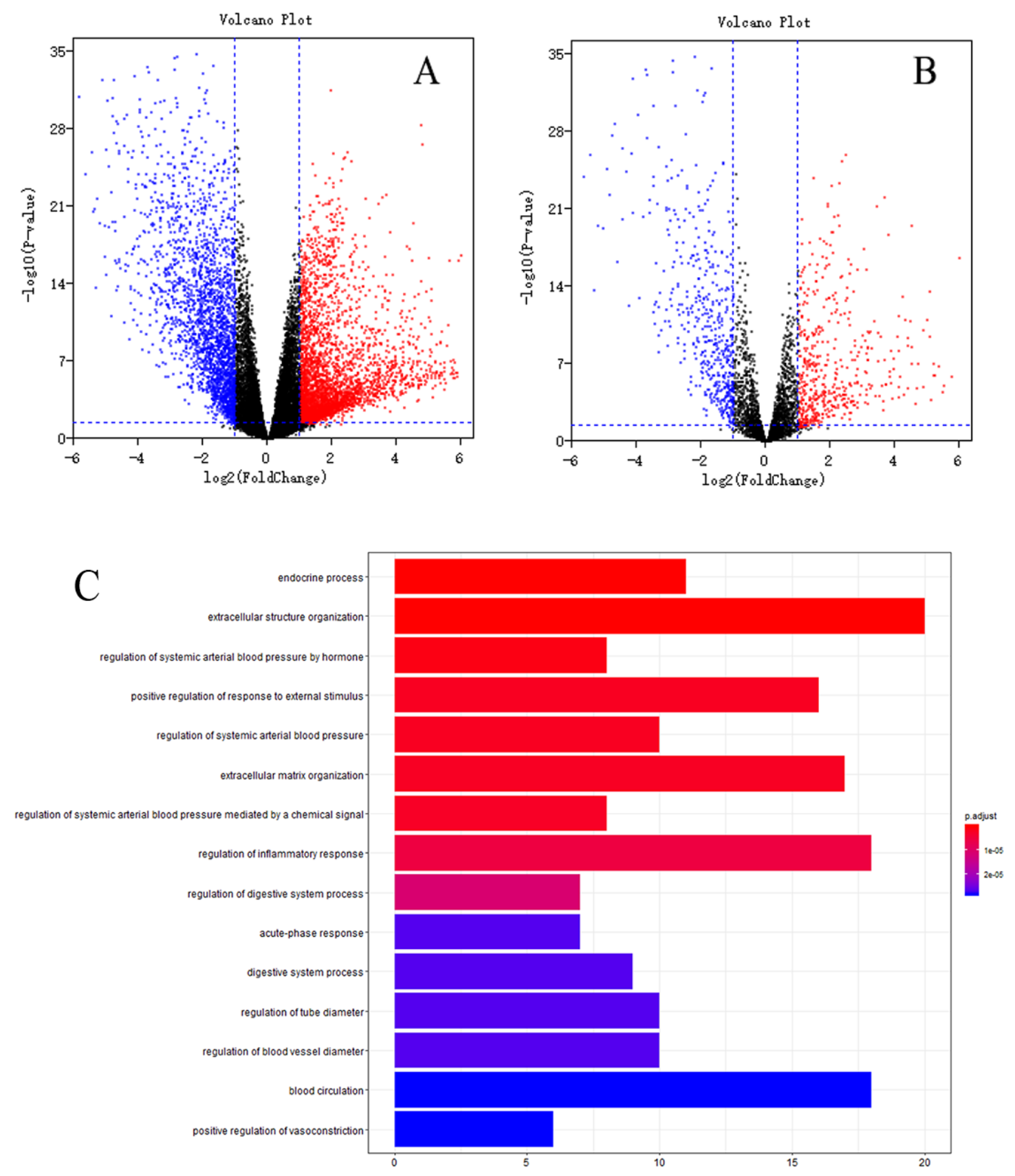

Figure 1. Differentially expression and gene functional: (A). Volcano chart of differentially expressed genes; (B). Volcano chart of immune differentially expressed genes; (C). Barplot chart for functional enrichment analysis 
Differentially expression and gene functional

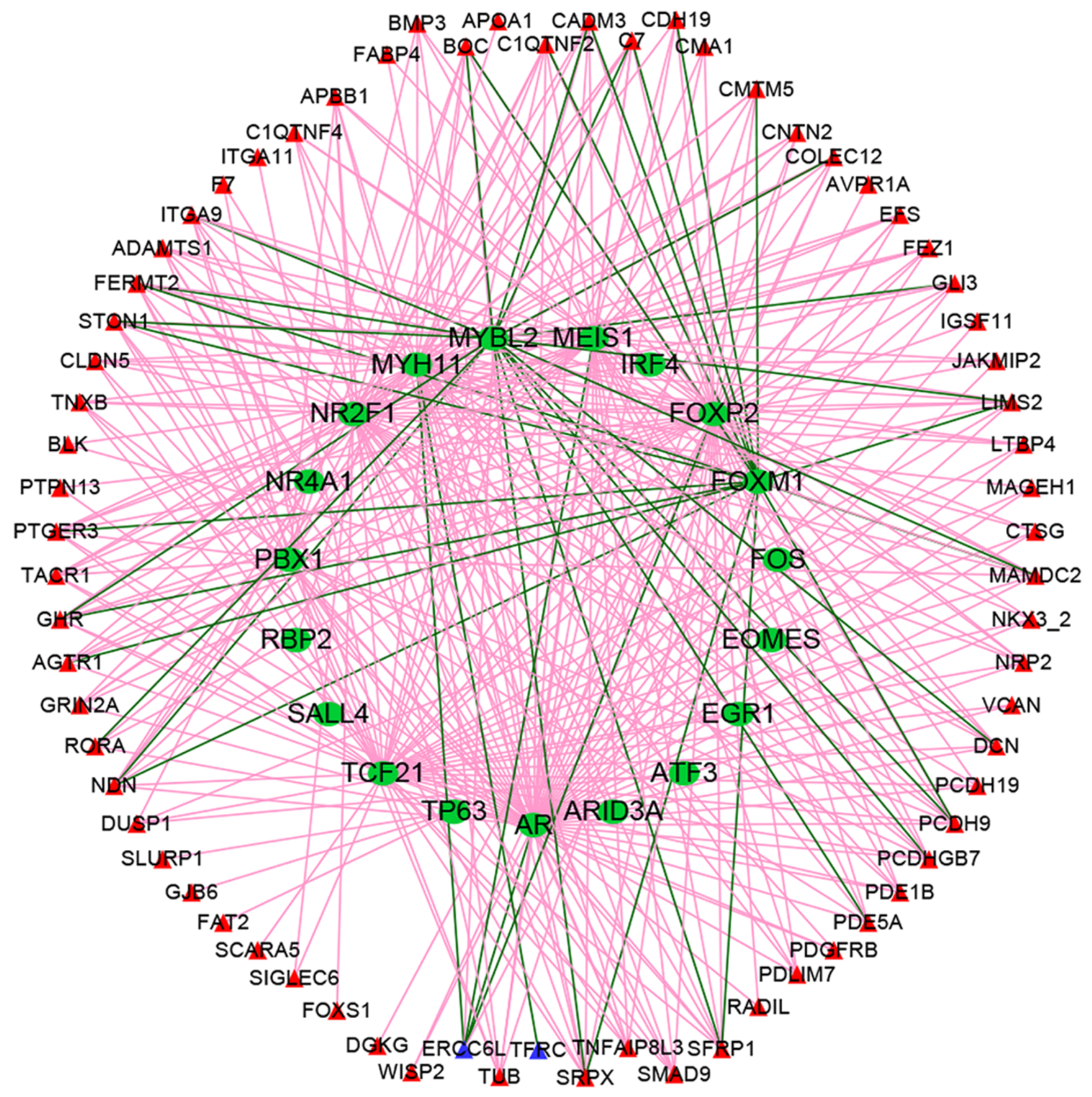

Figure 2. Immune gene regulatory network chart

Figure 2

Immune gene regulatory network chart 


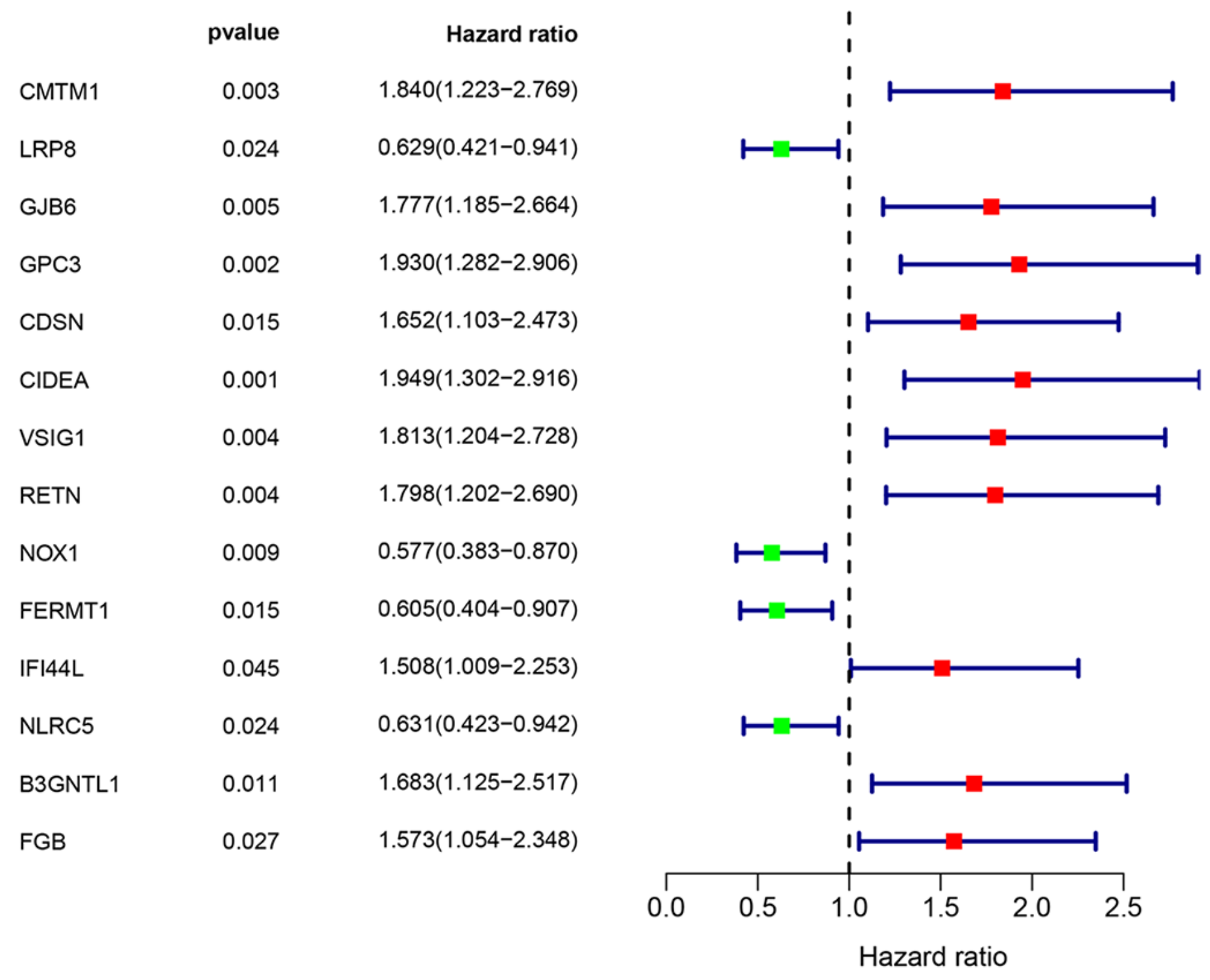

Figure 3. Immune gene survival forest chart

Figure 3

Immune gene survival forest chart 

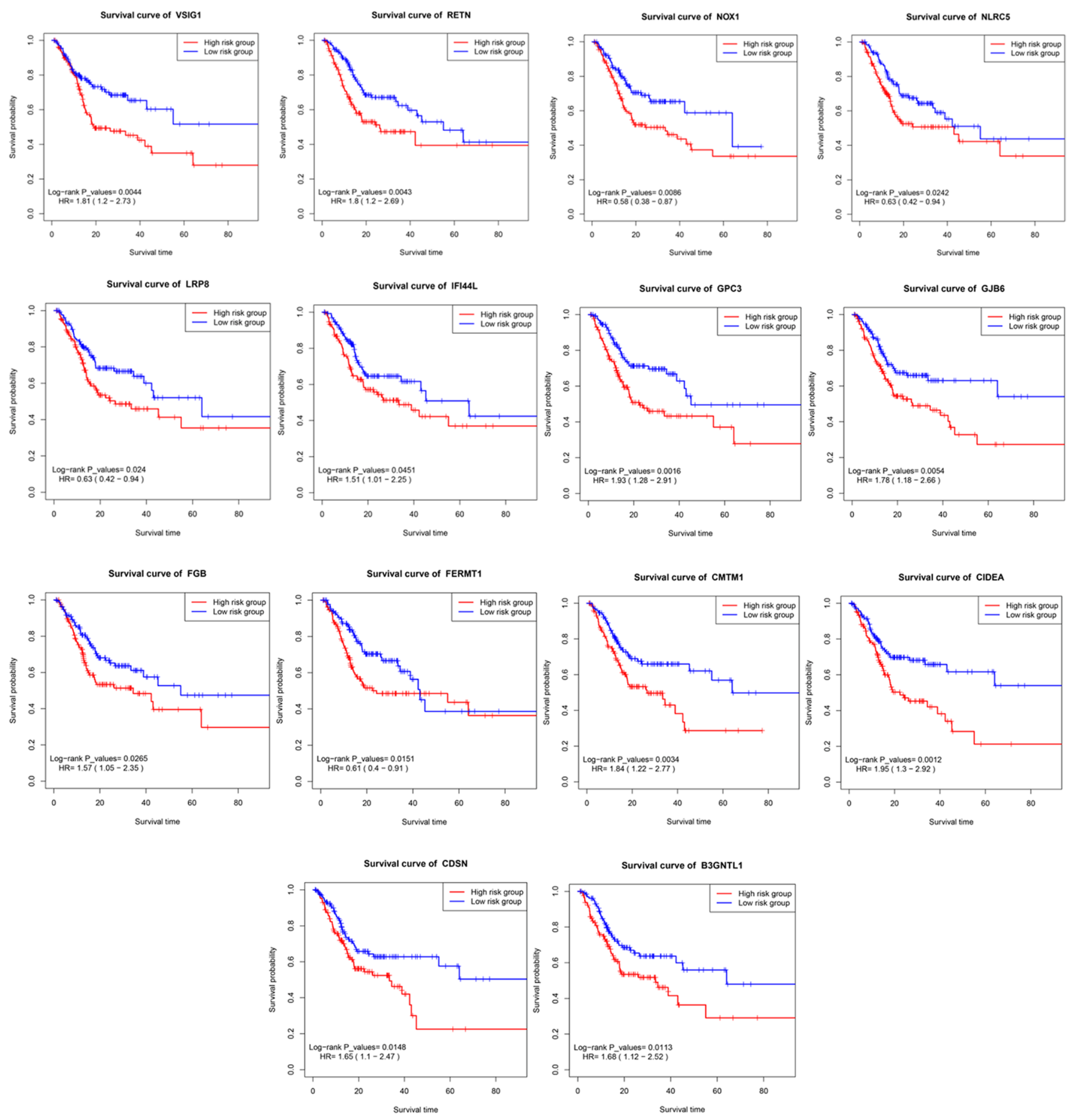

Figure 4. Survival curves of immune genes

\section{Figure 4}

Survival curves of immune genes. 
Nomogram predictive chart

Points

CMTM1

LRP8

GJB6

GPC3

CDSN

CIDEA

VSIG1

RETN

NOX1

FERMT1

IFI44L

NLRC5

B3GNTL1

FGB

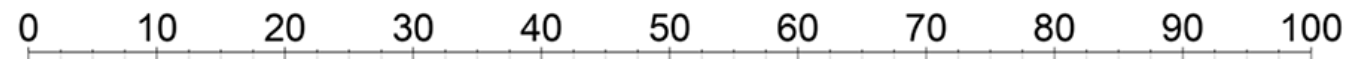

Total Points

1-year survival

3-year survival

5-year survival

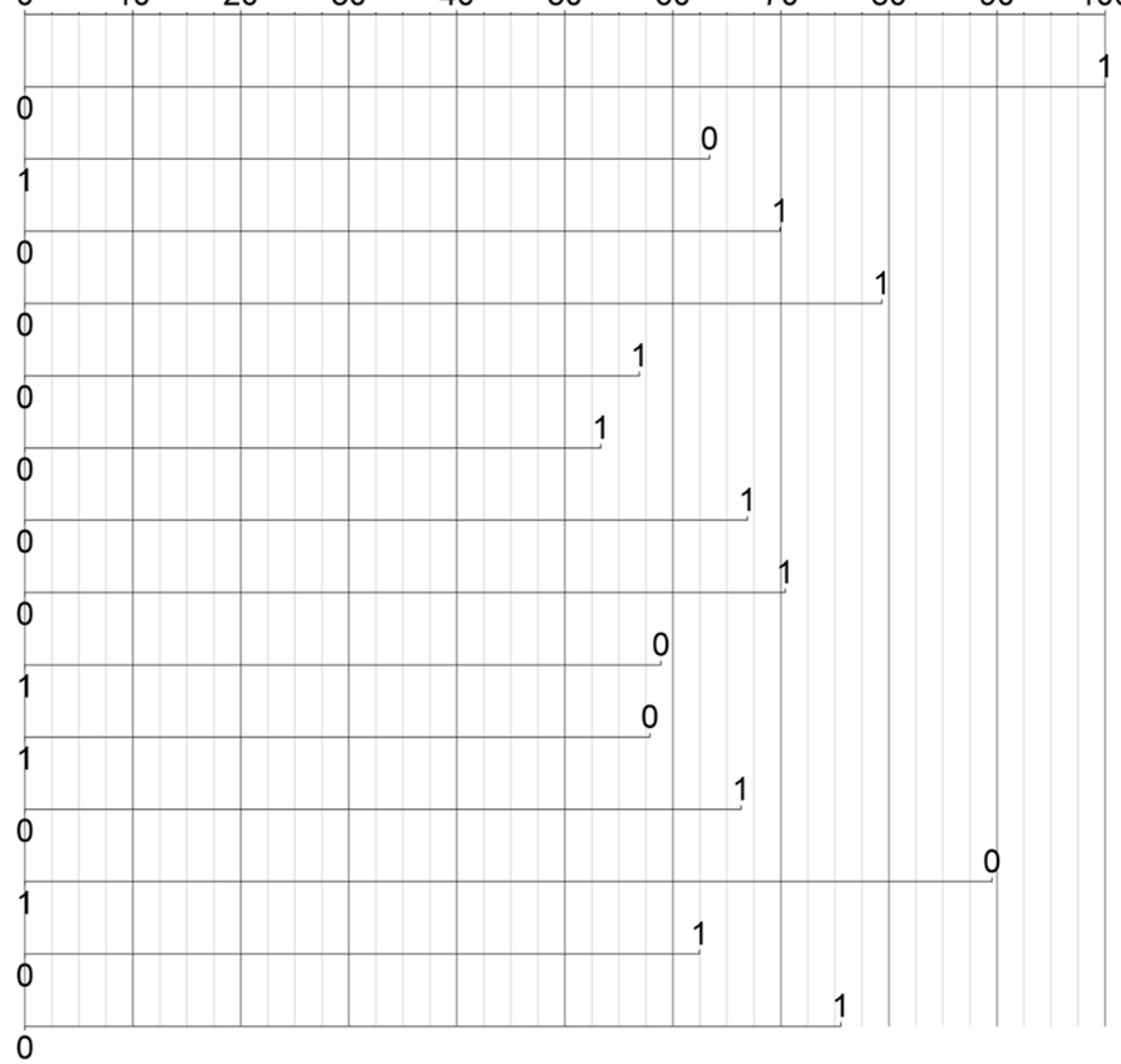

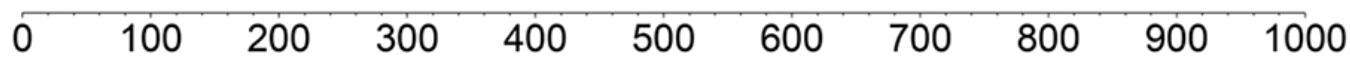

$\begin{array}{lllllll}0.95 & 0.9 & 0.8 & 0.6 & 0.4 & 0.2 & 0.05\end{array}$

$\begin{array}{lllllll}0.95 & 0.9 & 0.8 & 0.6 & 0.4 & 0.2 & 0.05\end{array}$

$\begin{array}{lllllll}0.95 & 0.9 & 0.8 & 0.6 & 0.4 & 0.2 & 0.05\end{array}$

Figure 5. Prognostic nomogram chart

Figure 5

Prognostic nomogram chart 
Survival curve chart

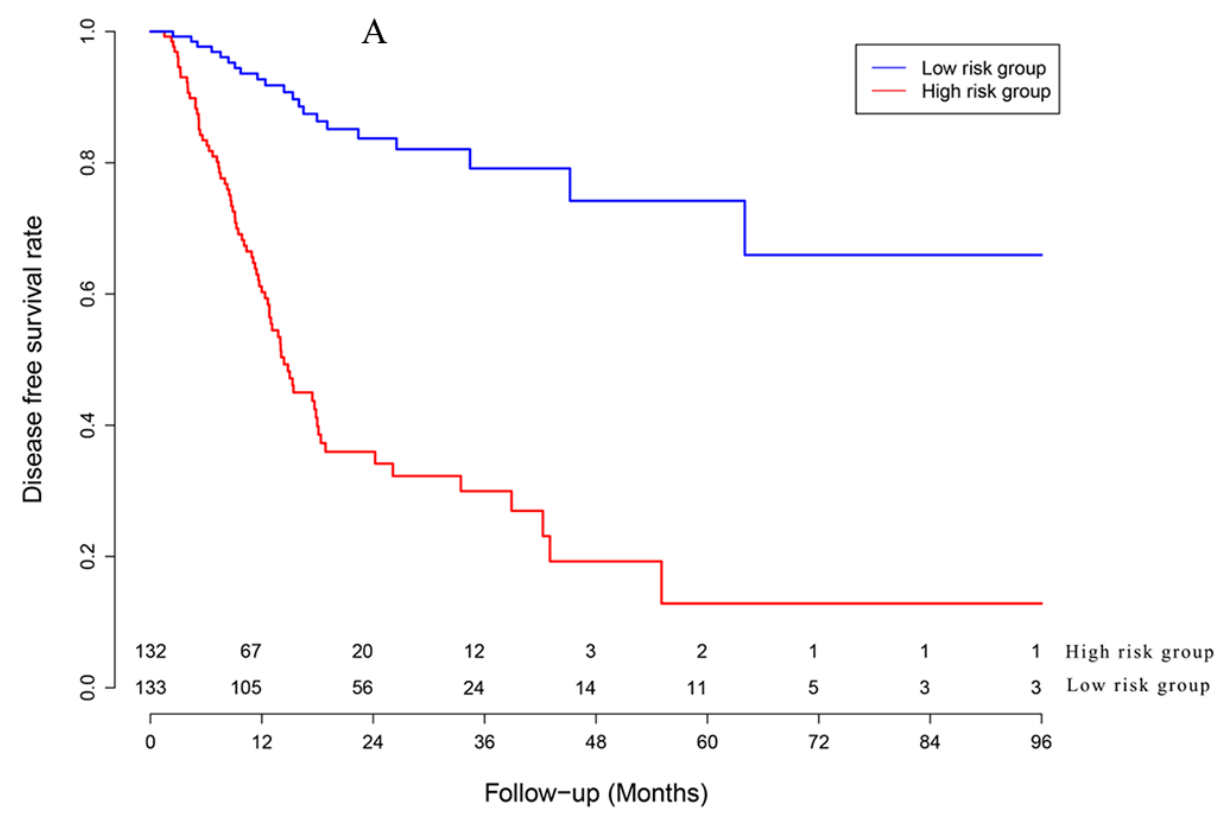

Time dependent receiver operating characteristic curve

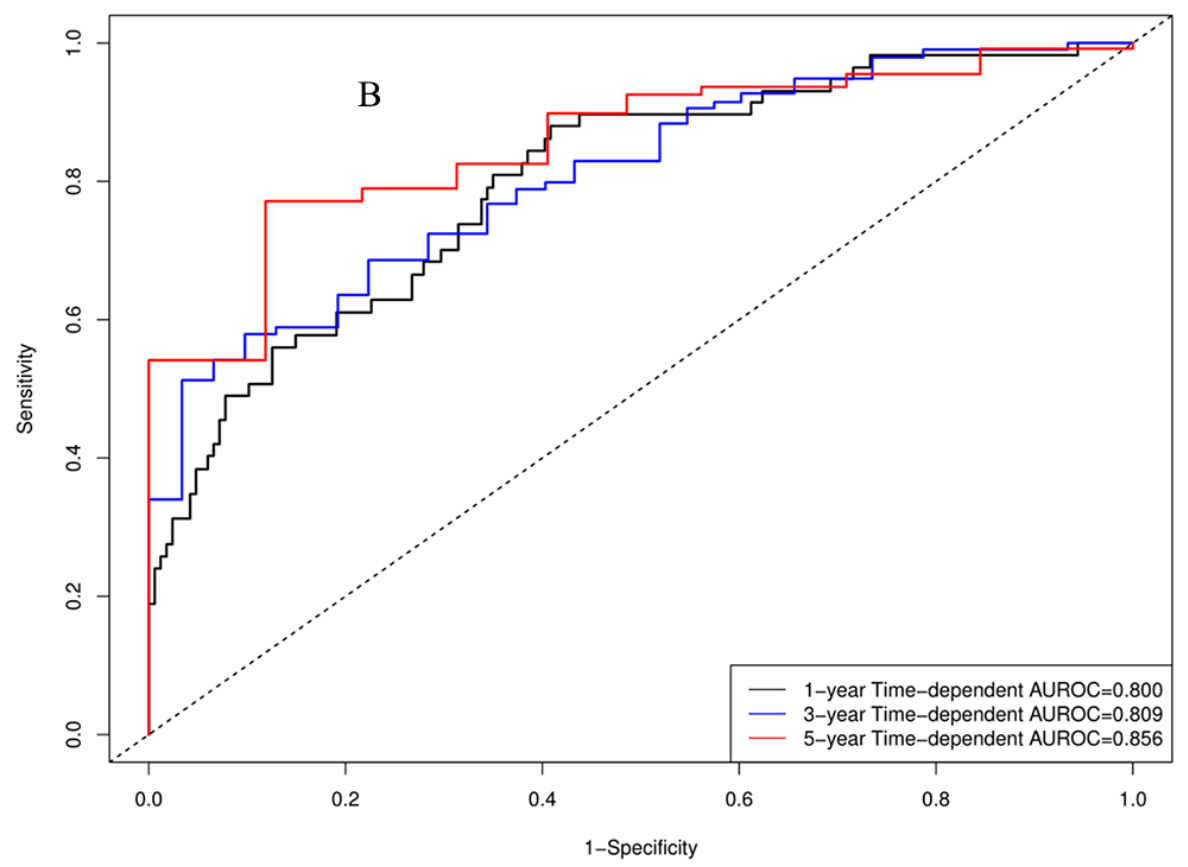

Figure 6. Clinical performance in model cohort: (A). Survival curves for high risk group and low risk group; (B). Time-dependent receiver operating characteristic curves

\section{Figure 6}

Clinical performance in model cohort 
Survival curve chart

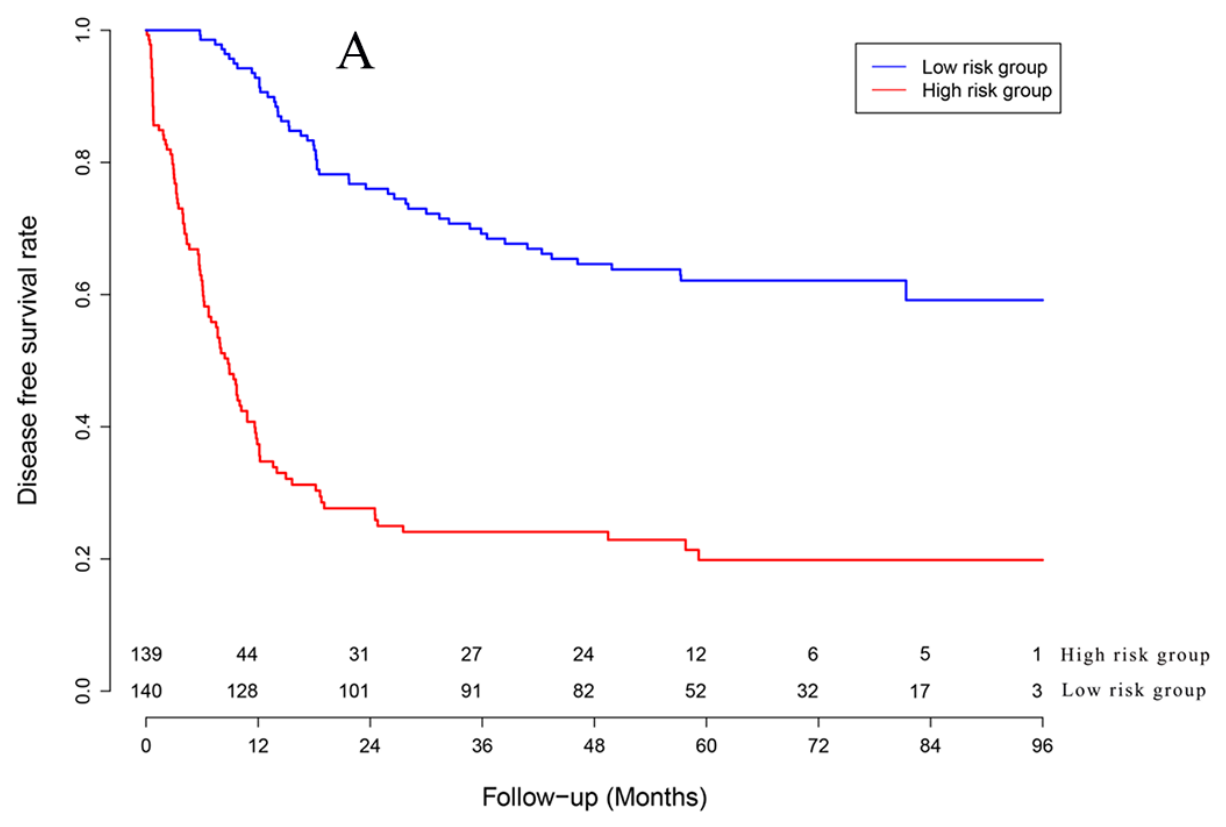

Time dependent receiver operating characteristic curve

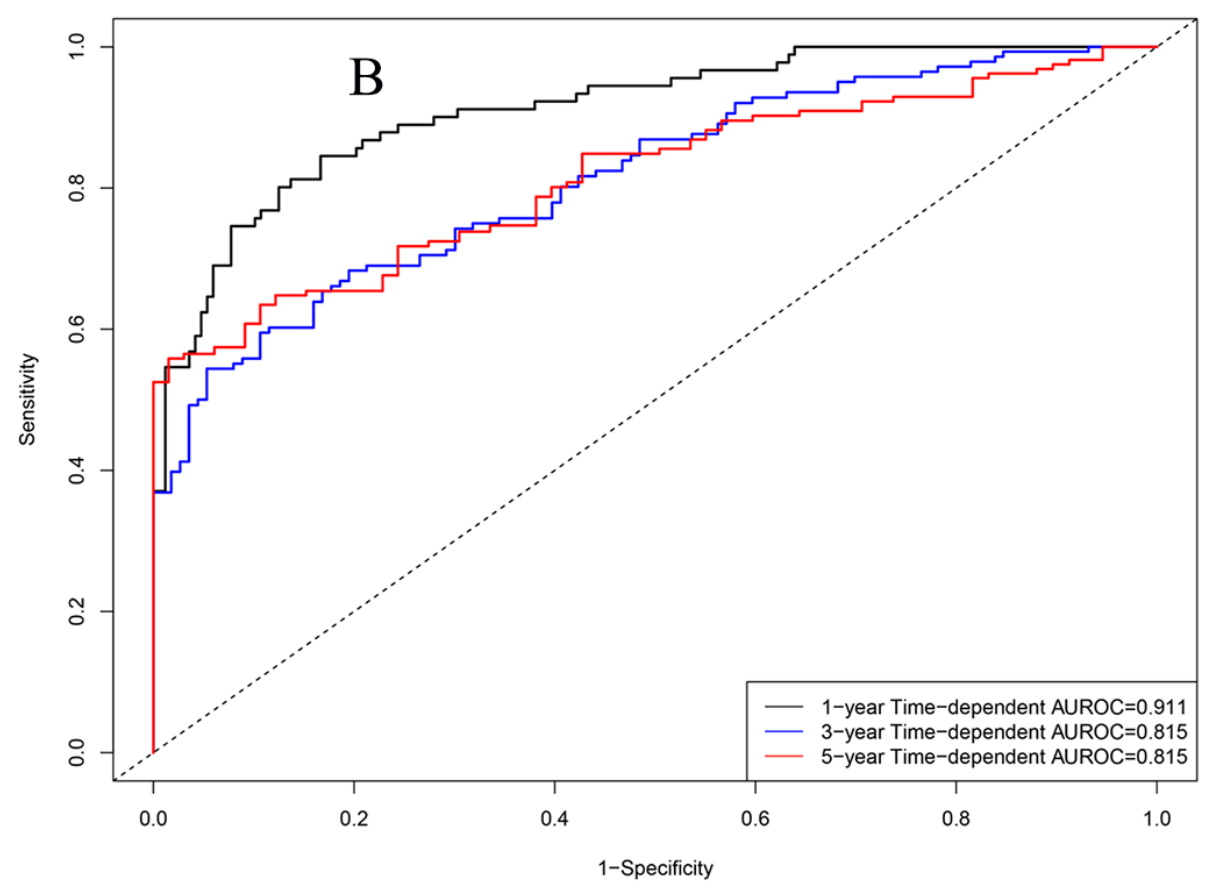

Figure 7. Clinical performance in validation cohort: (A). Survival curves for high risk group and low risk group; (B). Time-dependent receiver operating characteristic curves

\section{Figure 7}

Clinical performance in validation cohort 

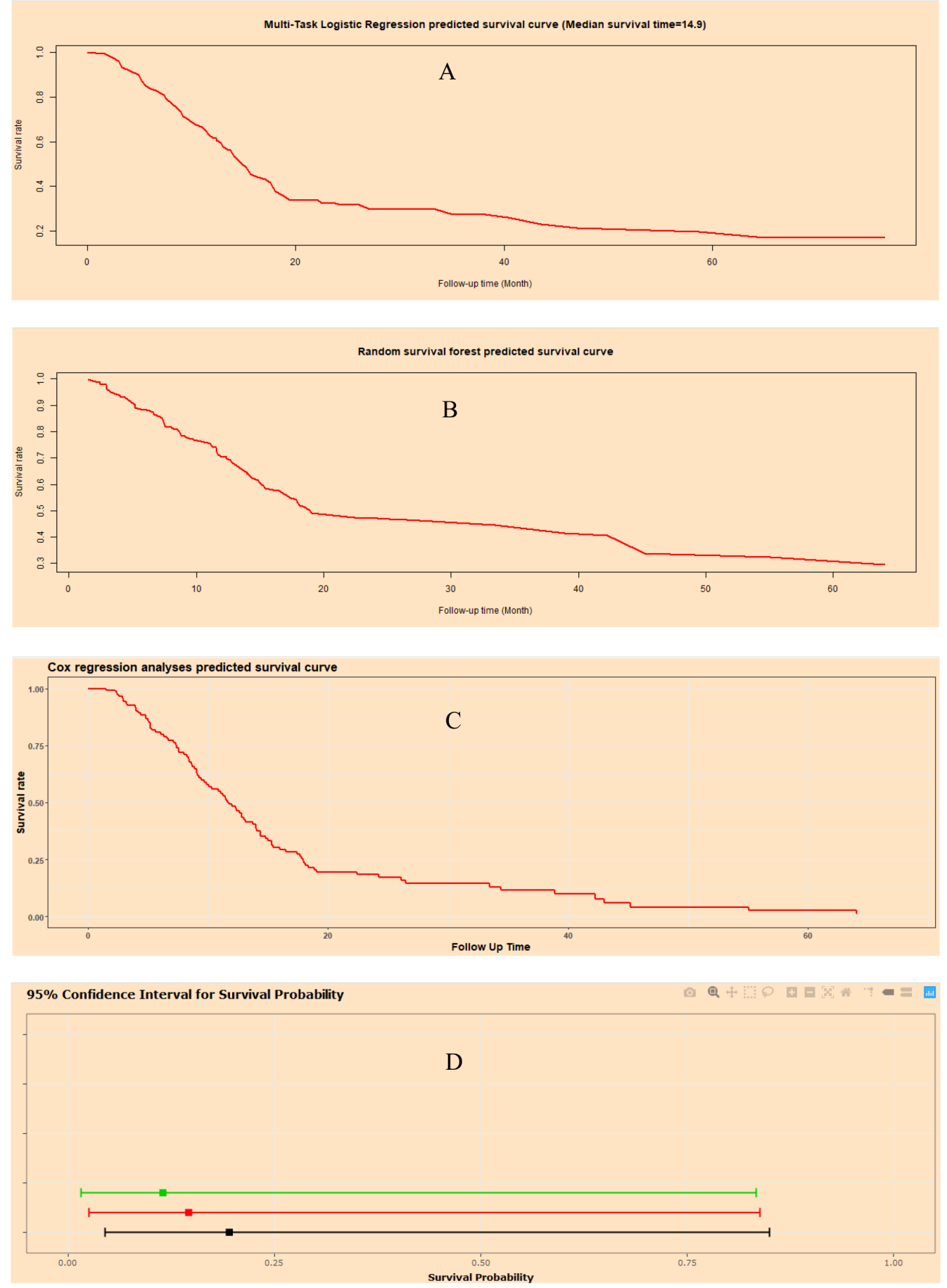

Figure 8. Home page of Smart Cancer Survival Predictive System: (A). Multi-Task logistic regression predicted survival curves; (B). Random survival forest predicted survival curves; (C). Cox survival regression predicted survival curves; (D). Cox survival regression predicted mortality percentage and $95 \%$ confidence interval.

\section{Figure 8}

Home page of artificial algorithm survival predictive system 

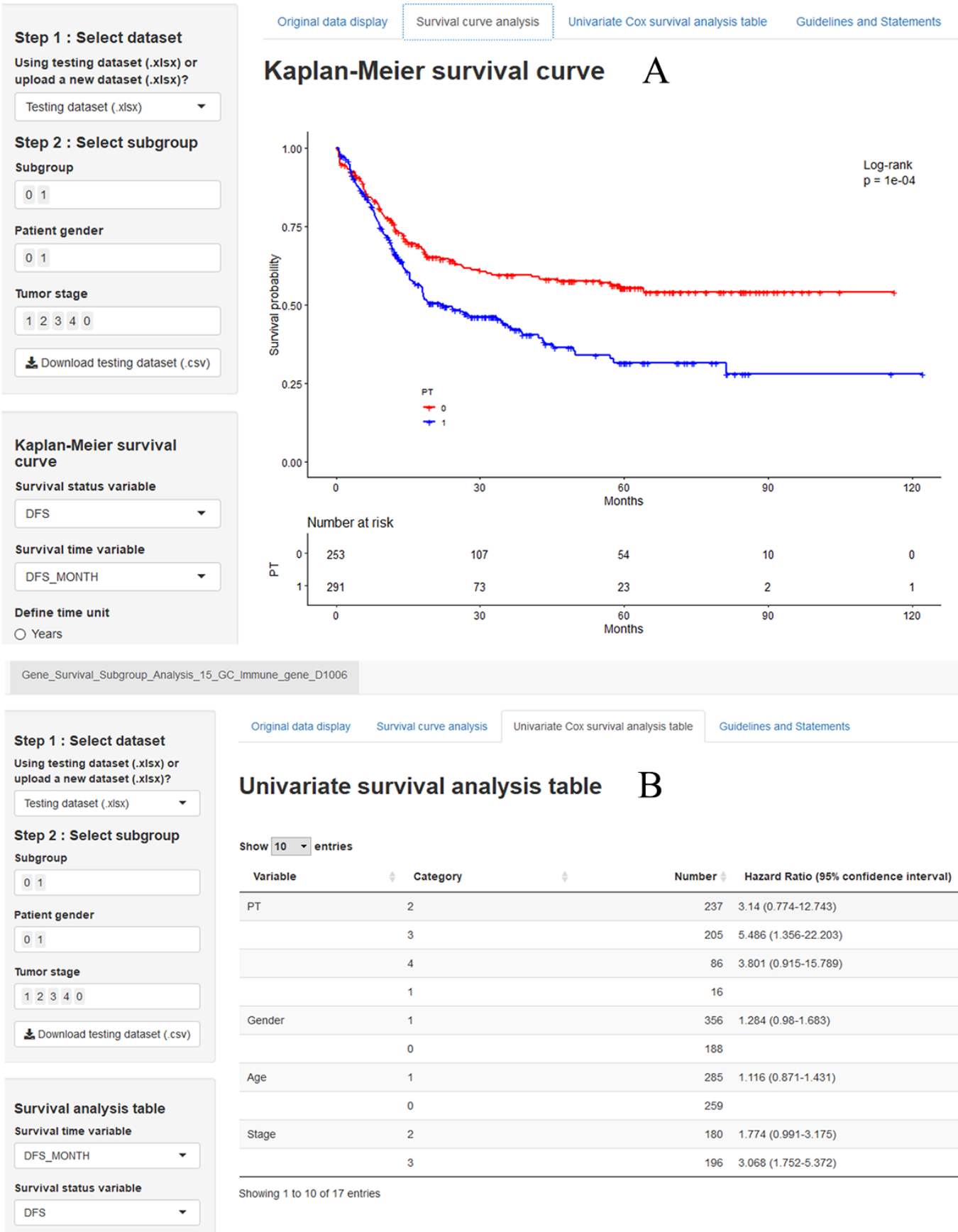

\section{Univariate survival analysis table $\mathrm{B}$}

\begin{tabular}{llrl}
$\begin{array}{l}\text { Show } 10 \text { - entries } \\
\text { Variable }\end{array}$ & Category & Number & Hazard Ratio (95\% confidence interval) \\
\hline PT & 2 & 237 & $3.14(0.774-12.743)$ \\
\hline & 3 & 205 & $5.486(1.356-22.203)$ \\
\hline & 4 & 86 & $3.801(0.915-15.789)$ \\
\hline Gender & 1 & 16 & \\
\hline & 1 & 356 & $1.284(0.98-1.683)$ \\
\hline Age & 0 & 188 & \\
\hline & 1 & 285 & $1.116(0.871-1.431)$ \\
\hline Stage & 0 & 259 & \\
\hline & 2 & 180 & $1.774(0.991-3.175)$ \\
\hline
\end{tabular}

Figure 9. Home page of Gene Survival Analysis Screen System: (A). Survival curves display page depicted and compared the survival curve between two defined subgroups; (B).Univariate survival analysis display page displayed results of univariate survival analysis for selected variables. Gene Survival Analysis Screen System allows users define different subgroups by themselves. Users are free to download, upload, and select the dataset for gene survival analysis.

\section{Figure 9}

Home page of Gene Survival Analysis Screen System 


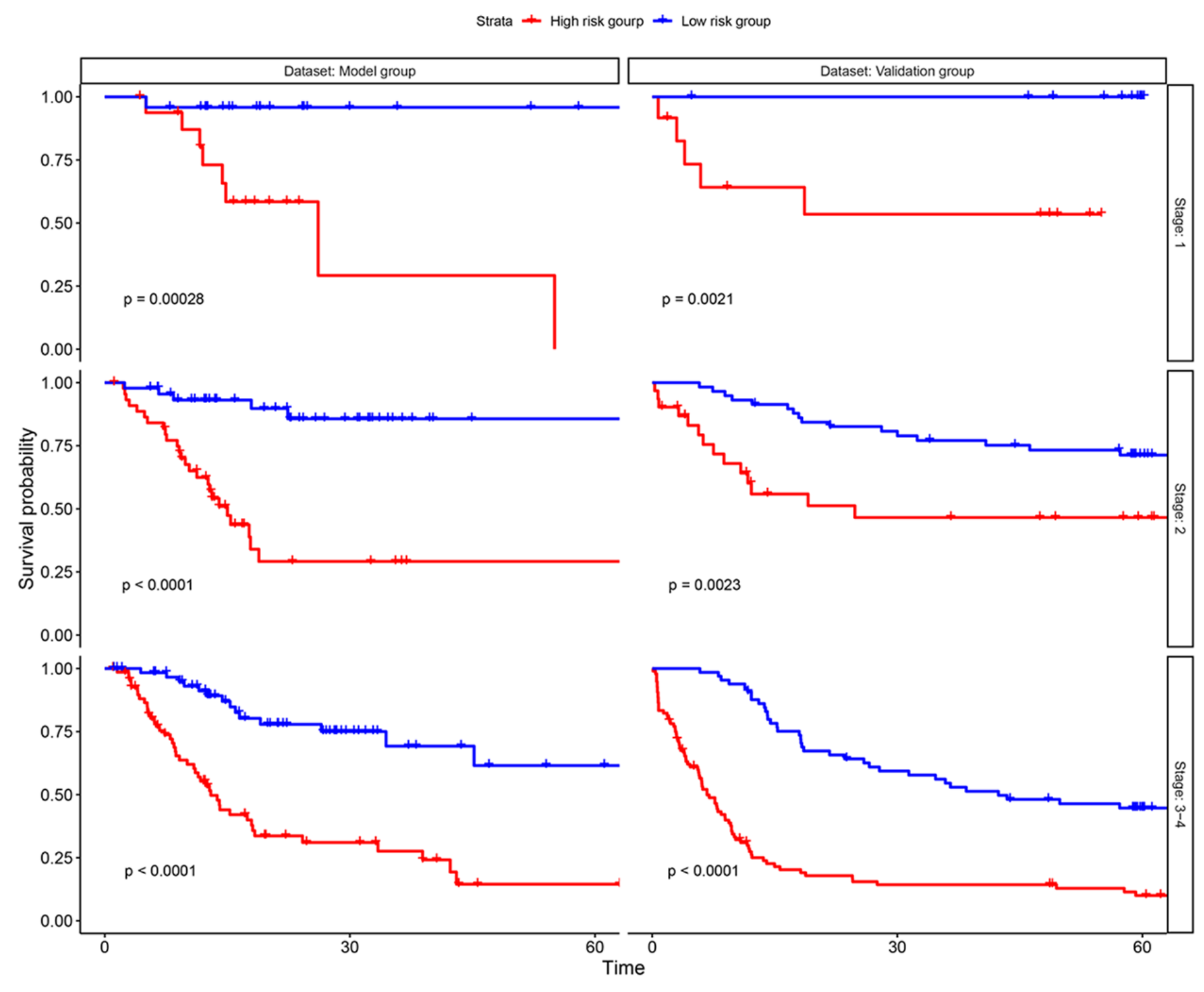

Figure 10. Survival curve subgroup analysis

Figure 10

Survival curve subgroup analysis 
Correlation coefficient heatmap

\begin{tabular}{|c|c|c|c|c|c|c|c|c|}
\hline-0.00 & 0.12 & 0.10 & 0.01 & 0.11 & -0.03 & 0.04 & 0.05 & CMTM1 \\
\hline-0.00 & 0.24 & 0.03 & 0.13 & 0.00 & -0.03 & -0.13 & 0.05 & LRP8 \\
\hline-0.03 & -0.05 & -0.02 & -0.03 & -0.03 & 0.09 & -0.08 & 0.08 & GJB6 \\
\hline 0.03 & -0.18 & 0.03 & 0.05 & 0.13 & 0.06 & 0.01 & 0.05 & GPC3 \\
\hline 0.02 & 0.13 & -0.13 & 0.07 & -0.01 & -0.07 & -0.16 & -0.00 & CDSN \\
\hline-0.00 & -0.17 & -0.06 & -0.01 & -0.01 & 0.08 & 0.17 & -0.05 & CIDEA \\
\hline-0.13 & -0.14 & 0.12 & -0.02 & 0.14 & 0.08 & -0.08 & 0.05 & VSIG1 \\
\hline 0.11 & 0.04 & 0.03 & 0.02 & 0.03 & 0.01 & 0.15 & -0.04 & RETN \\
\hline-0.01 & 0.11 & -0.03 & 0.08 & -0.01 & 0.06 & -0.18 & -0.01 & NOX1 \\
\hline-0.03 & 0.06 & 0.03 & 0.08 & 0.06 & 0.00 & -0.17 & 0.02 & FERMT1 \\
\hline-0.05 & -0.11 & 0.15 & 0.21 & 0.13 & 0.03 & 0.14 & -0.01 & IFI44L \\
\hline-0.02 & 0.04 & 0.07 & 0.08 & 0.05 & 0.00 & 0.03 & 0.05 & NLRC5 \\
\hline 0.09 & 0.10 & 0.01 & -0.02 & 0.10 & -0.03 & -0.05 & 0.08 & B3GNTL1 \\
\hline 0.07 & 0.02 & 0.18 & 0.06 & 0.09 & 0.00 & 0.02 & -0.04 & FGB \\
\hline 0.04 & -0.15 & 0.09 & -0.00 & 0.15 & 0.05 & 0.14 & 0.02 & Predict_value \\
\hline$d^{e^{x}}$ & $p g^{\theta}$ & $0^{29^{8}}$ & Q & $p^{r}$ & $e^{N}$ & & to & \\
\hline
\end{tabular}

Figure 11.Clinical variable correlation coefficient heatmap

Figure 11

Clinical variable correlation coefficient heatmap 
Correlation coefficient heatmap

\begin{tabular}{|c|c|c|c|c|c|c|}
\hline-0.07 & 0.00 & -0.06 & 0.00 & -0.10 & 0.05 & CMTM1 \\
\hline-0.07 & -0.19 & -0.14 & -0.06 & -0.33 & -0.15 & LRP8 \\
\hline-0.02 & -0.03 & -0.16 & -0.12 & -0.07 & -0.15 & GJB6 \\
\hline-0.02 & 0.21 & -0.07 & -0.06 & 0.26 & 0.06 & GPC3 \\
\hline-0.06 & -0.04 & -0.21 & -0.09 & -0.07 & -0.17 & CDSN \\
\hline 0.06 & 0.20 & -0.02 & -0.02 & 0.25 & 0.07 & CIDEA \\
\hline 0.13 & 0.07 & 0.03 & 0.01 & -0.01 & 0.00 & VSIG1 \\
\hline-0.16 & -0.03 & 0.06 & 0.24 & 0.19 & 0.25 & RETN \\
\hline-0.11 & -0.08 & -0.02 & 0.01 & -0.08 & -0.06 & NOX1 \\
\hline-0.25 & -0.15 & -0.17 & -0.12 & -0.24 & -0.20 & FERMT1 \\
\hline 0.01 & 0.24 & 0.28 & 0.39 & 0.27 & 0.37 & IF|44L \\
\hline 0.13 & 0.20 & 0.27 & 0.30 & -0.08 & 0.28 & NLRC5 \\
\hline 0.02 & 0.01 & -0.20 & -0.14 & -0.16 & -0.11 & B3GNTL1 \\
\hline-0.10 & -0.12 & -0.04 & -0.07 & -0.08 & -0.05 & FGB \\
\hline-0.00 & 0.10 & -0.04 & 0.03 & 0.27 & 0.10 & Predict_value \\
\hline$\sigma^{ل}$ & & & & & & \\
\hline
\end{tabular}

Figure 12.Immune gene correlation coefficient heatmap

Figure 12

Immune gene correlation coefficient heatmap 

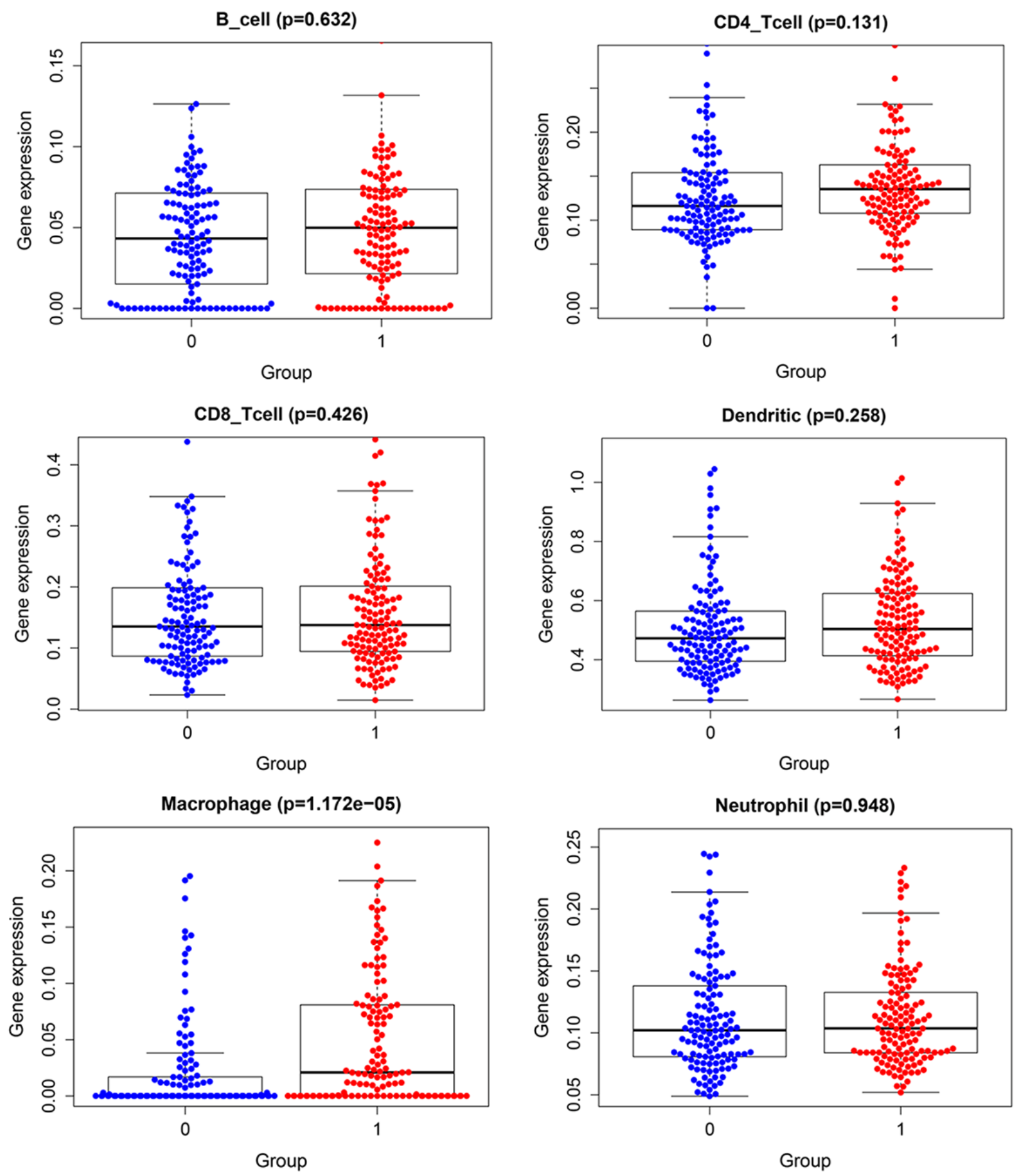

Figure 13. Expression of tumor immune infiltrating cells

Figure 13

Expression of tumor immune infiltrating cells 

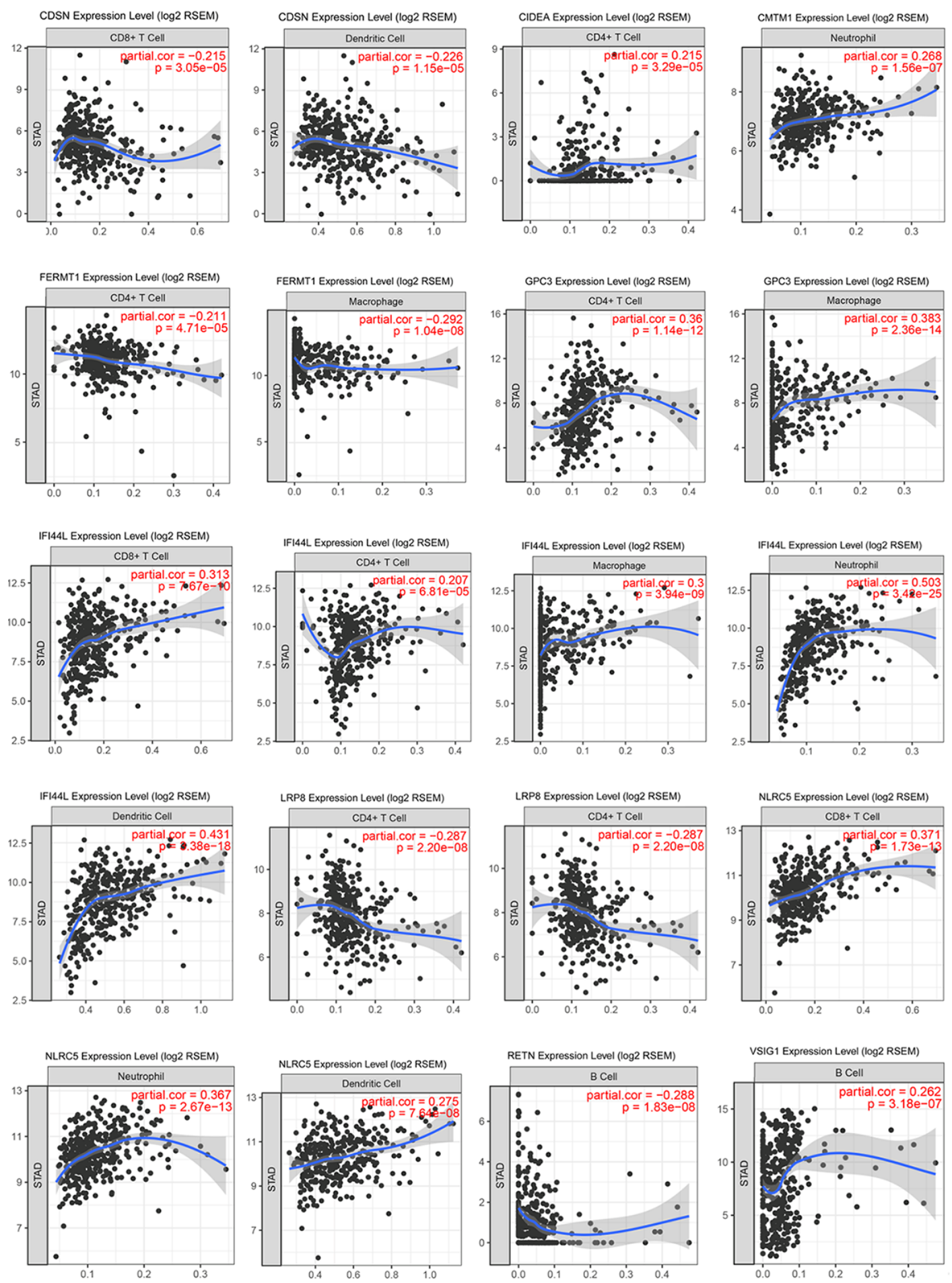

Infiltration Level

Figure 14. Scatter plot between tumor infiltrating immune cells and immune genes

\section{Figure 14}

Scatter plot between tumor infiltrating immune cells and immune genes 

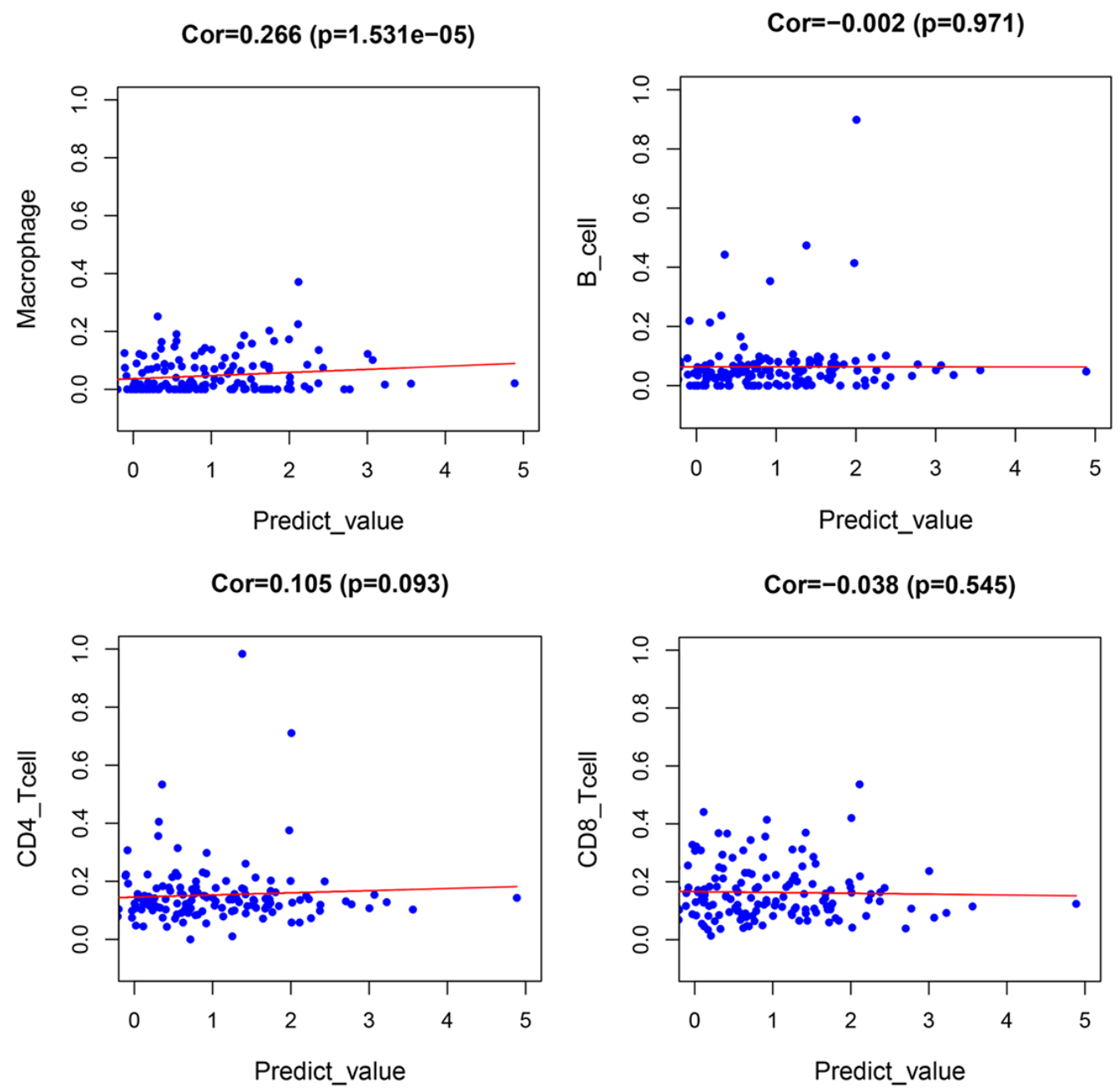

Cor=0.100 $(p=0.109)$

Predict_value
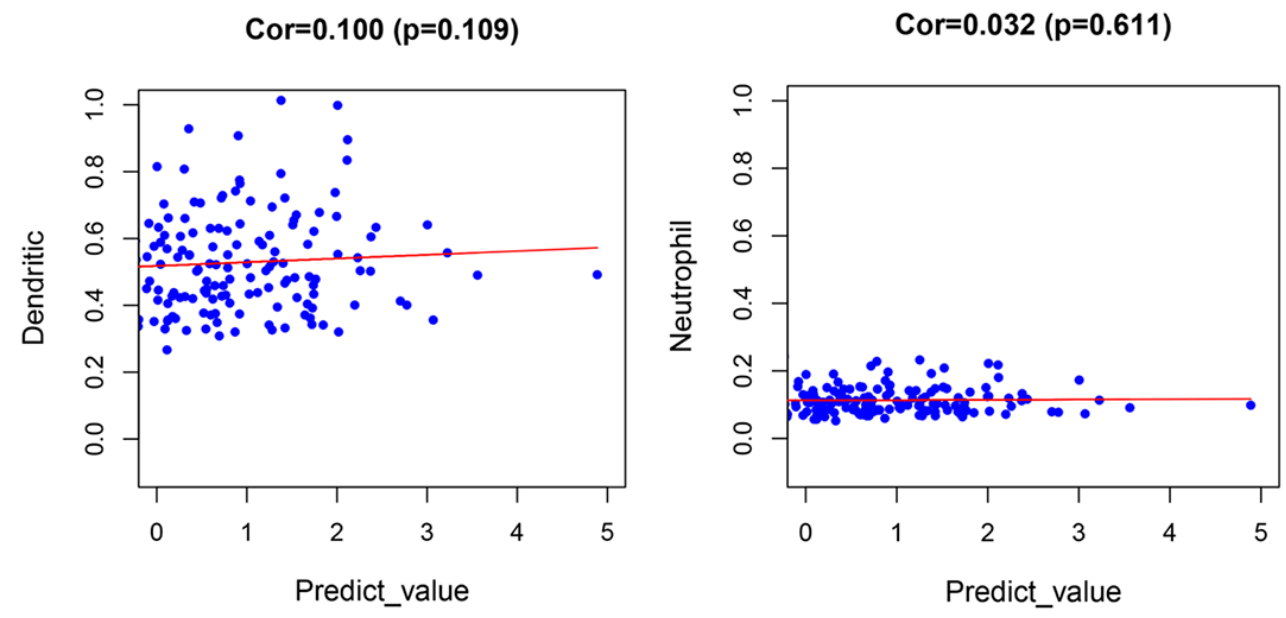

Figure 15. Scatter plot between tumor infiltrating immune cells and prognostic signature

\section{Figure 15}

Scatter plot between tumor infiltrating immune cells and prognostic signature

\section{Supplementary Files}

This is a list of supplementary files associated with this preprint. Click to download. 
- 20200610D1006Suppementaryfiguremergedocuments.pdf 